Historic, archived document

Do not assume content reflects current scientific knowledge, policies, or practices. 
USDA Forest Service

Research Paper INT-80

1970

\section{MEASUREMENT OF WATER POTENTIAL WITH THERMOCOUPLE PSYCHROMETERS: CONSTRUCTION AND APPLICATIONS}

\section{Ray W. Brown}
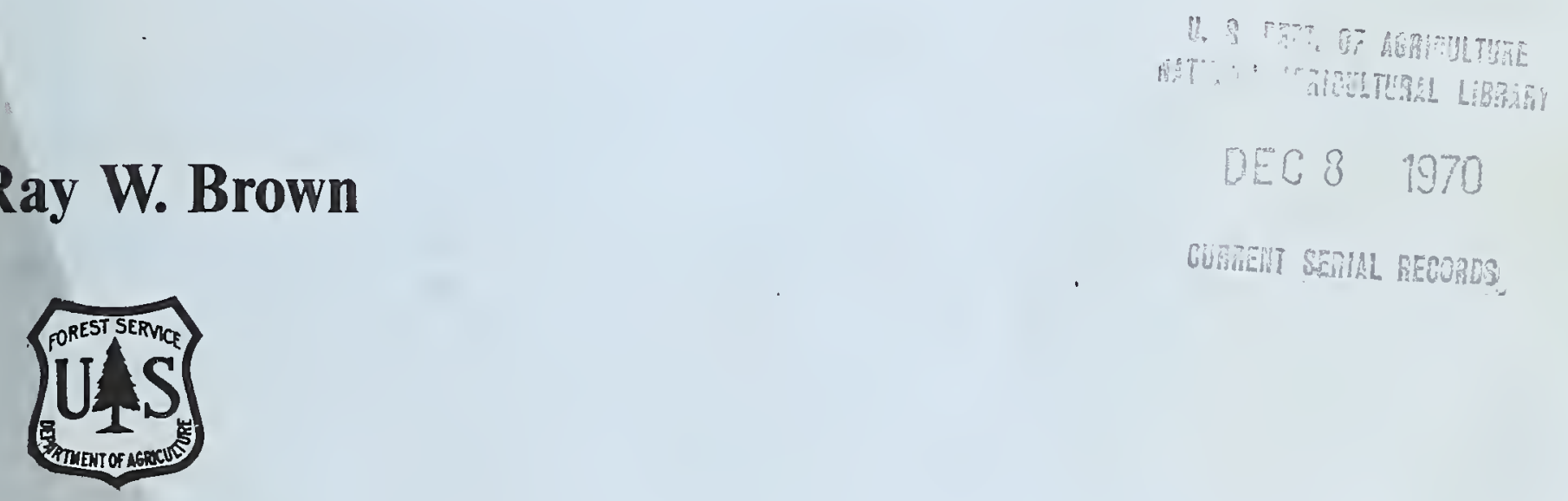

INTERMOUNTAIN FOREST AND RANGE EXPERIMENT STATION Ogden, Utah 84401 

USDA, National Agricultural Library

NAL Bldg

10301 Baltimore Blvd

USDA Forest Service

Beltsville, MD 20705-2351

Research Paper INT-80

1970

\section{MEASUREMENT OF WATER POTENTIAL WITH THERMOCOUPLE PSYCHROMETERS: CONSTRUCTION AND APPLICATIONS}

Ray W. Brown

INTERMOUNTAIN FOREST AND RANGE EXPERIMENT STATION

Forest Service

U.S. Department of Agriculture

Ogden, Utah 84401

Joseph F. Pechanec, Director 


\section{THE AUTHOR}

RAY W. BROWN, Plant Physiologist on the Watershed Rehabilitation project at Logan, Utah, joined the staff of the Intermountain Station in 1965. He holds a B. S. degree in Forestry and an M.S. in Range Ecology from the University of Montana. He is currently completing the requirements for a Ph. D. in Plant Physiology at Utah State University. 


\section{CONTENTS}

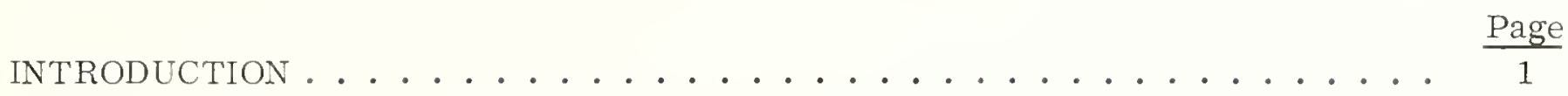

STATE OF WATER IN THE SOIL-PLANT-ATMOSPHERE CONTINUUM $\ldots . . .2$

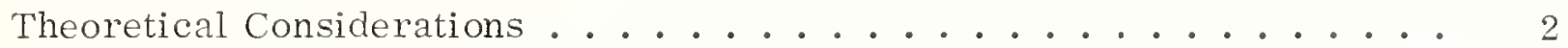

Components of Water Potential ....................... 3

METHODS OF MEASURING WATER POTENTIAL . . . . . . . . . 5

Nonpsychrometric Methods ...................... 5

The Thermocouple Psychrometer Method ............ 5

IMPROVED DESIGN CRITERIA FOR THERMIOCOUPLE PSYCHROMETERS . . . 10

Considerations of Instrument Design . . . . . . . . . . 10

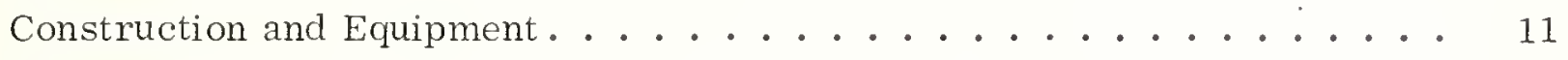

Calibration and Measurement Procedures ............. 13

Psychrometer Response to Changing Water Potentials . . . . . . 16

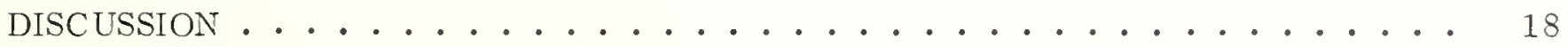

Evaluation of Thermocouple Psychrometers . . . . . . . . 18

Potential Uses of Thermocouple Psychrometers . . . . . . . . 19

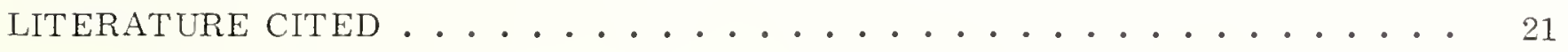

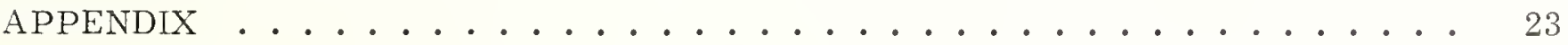




\section{ABSTRACT}

Basic theory of water potential in the soil-plant-atmosphere continuum is considered, together with a review of the use of thermocouple psychrometers. The construction, methods of water potential measurement, and calibration of thermocouple psychrometers are discussed in detail. The effects of protective ceramic cups on the rate of water vapor exchange between the soil mass and the internal psychrometer cavity are compared with the effects of fine screen cups. The ceramic cup imposes a much greater resistance to vapor exchange than the screen cups; the magnitudes of possible errors resulting from this resistance in estimates of water potential are discussed. Possible uses of thermocouple psychrometers for measuring water potentials of soils and plants under intensive forest management practices are considered.

The use of trade, firm, or corporation names in this publication is for the information and convenience of the reader. Such use does not constitute an official endorsement or approval by the U.S. Department of Agriculture of any product or service to the exclusion of others which may be suitable. 


\section{INTRODUCTION}

In recent years, researchers in the environmental sciences have become interested in developing a means of measuring and expressing the free energy status of water in the soil-plant-atmosphere continuum. During the last decade a substantial amount of research was devoted to this problem, and from this has emerged a whole new theoretical approach based on thermodynamic principles and terminology. This research marked a notable turning point in the science of soil-plant water relations; also, these studies offered a fresh insight into the question of water and energy transfer. Certainly, some of the most important contributions emanating from this work are the great number of experimental techniques and methods now available for research in water relations. The principal technique, thermocouple psychrometry, is used to describe the free energy status of water in the soil-plant continuum in quantitative terms consistent with modern thermodynamic theory.

There is abundant literature dealing with the specific details of construction and the theory of operation of these instruments; however, this literature is rather extensive and specialized. It is the purpose here to briefly review the theoretical considerations of water relations, to review the more pertinent aspects of thermocouple psychrometry, and to describe in detail the construction, calibration, and use of a rapid-response thermocouple psychrometer designed for measuring the free energy status of water in the dynamic soil-plant complex.

Measurement of the free energy status of water is essential to studies of the relationships between water in the soil and in plants and its consequent loss to the atmosphere. Water in the soil-plant-atmosphere continuum is dynamic and is rarely, if ever, in equilibrium with water in adjacent locations. The driving forces responsible for water transfer are gradients of decreasing free energy resulting from plant transpiration, evaporation, vapor pressure gradients, temperature gradients, and various other forces. Thus, water in the soil-plant-atmosphere continuum follows a gradient of decreasing free energy from the soil, through the plant, out to the atmosphere. During periods of high transpiration demand, particularly steep energy gradients may result within very small distances between the soil and roots, within the plant itself, and between the plant and surrounding atmosphere. Plant responses to water stress are more closely related to the energy required to remove a unit of water from the soil than any other single factor. Therefore, to be most useful, measurements of water in dynamic systems should include as many aspects of the component factors controlling water transfer as possible.

There are a number of methods available for describing the water status in soils and plants; these methods are mainly based on measurements of water quantity. However, an alternate method based on determination of water-free energy also offers many advantages. One of the most obvious advantages of this latter method is that of directly expressing soil water in terms of the energy required for the removal of a unit of water from the soil by plants. Measurements of soil water energy have merit because they are more directly comparable among different textural classes. A given soil water energy level has the same implications with respect to root absorption, evaporation, or other forces, regardless of the physical properties of the soil. Also, recent advances in techniques now permit direct measurements of the in situ energy status of water in soils and plants with a minimum of disturbance. These measurements can be accomplished simultancously in soil and plants and results are expressed in the same meaningful terms. 


\section{STATE OF WATER IN THE SOIL - PLANT - ATMOSPHERE CONTINUUM Theoretical Considerations}

Transpiration loss by a plant results in reduced turgor pressure, and, consequent$1 y$, reduced potential energy of water in the leaves. This reduction of water creates an energy gradient in the water column from the soil through the roots and xylem tissue of the stem to the leaves. Actually, the transpiration process itself results from a decreasing energy gradient of the water from the leaves to the surrounding atmosphere. Thus, we can speak of a soil-plant-atmosphere continuum with respect to the gradient of decreasing free energy in water from the soil, to the plant, and out to the atmosphere. Evaporation from the soil surface also results from a decreasing energy gradient from the soil to the atmosphere. The driving force for water movement is the decreasing energy gradient of water in the system under consideration. Therefore, an understanding of the processes of water transfer must begin with the energy relations of soil and plant water in terms of thermodynamic principles. A brief review of these principles is presented here, but the interested reader is referred to the following references for a more rigorous mathematical treatment of the theoretical considerations of energy relations of water: Slatyer 1967; Gardner 1965; Kramer and others 1966; Tay'lor and others 1961; Taylor 1964, 1965; Taylor and Stewart 1960; Spanner 1964; and Briggs 1967.

The concept of energy status of water in a system is best explained in terms of free energy, or more correctly, Gibbs free energy (describes spontaneity). The free energy of a component (water, in this case) in a system (soil or the plant) is an expression of the capacity of the component to do work. The free energy of water depends on the mole fraction of water available or the concentration of the water molecules in the system relative to the concentration of other components in the same system. Since the actual free energy is difficult to calculate, the free energy of water in the soil or in plant tissue can be expressed as the difference between the free energy of pure free water and the free energy of the water in the system at the same temperature and pressure. The resulting net free energy of water has been referred to as the chemical potential, or the more widely accepted term, water potential (Slatyer and Taylor 1960, Taylor and Slatyer 1962).

The water potential is affected by factors that change the free energy of water molecules in the system. The presence of solutes (ionized or nonionized molecules), colloids (clay or very large molecules), large particles such as clays, silt, and sand, all decrease the water potential. The water molecules in the system, such as soil or a plant, interact with these components and decrease the free energy of the water below that of pure free water. Water potential can be defined, then, as the minimum additional work required to remove water from the soil (or any other system) in excess of the work required to remove pure free water from the same location. On the other hand, the partial specific Gibbs free energy, or the water potential of water in a multicomponent system, is an expression of the ability of a unit mass of water to do work compared to the work that an equal mass of pure free water can do. Since the presence of other components (such as solutes) reduces the free energy of water, the potential for water to do work in a multicomponent system is less than that of pure water, and thus the water potential will be negative.

The manner in which solutes and other components reduce the water potential in soil and plants can be expressed in terms of their effects on the chemical activity of water. "Activity" is a thermodynamic term for the tendency of water to react or move in a system, and this value is equal to the relative vapor pressure of the water in the system. Therefore, water potential is described in terms of the relative vapor pressure of the water in the system to that of pure free water at the same temperature and pressure, and can be written as: 


$$
-\psi=\operatorname{RT} \ln \frac{\mathrm{e}}{\mathrm{e}_{\mathrm{o}}}
$$

where,

$-\psi$ is the symbol for water potential, expressed as a negative value,

$\mathrm{R}$ is the universal gas constant,

$\mathrm{T}$ is the absolute temperature in ${ }^{\circ} \mathrm{K}$,

$\mathrm{e}$ is the actual vapor pressure of the water in the system,

$\mathrm{e}_{\mathrm{o}}$ is the vapor pressure of pure free water.

This equation implies that water potential is expressed in energy units, such as ergs mole $e^{-1}$, but these units are somewhat inconvenient to convert from energy units to pressure units (atmospheres or bars), in which case, equation (1) becomes:

$$
-\psi=\frac{\mathrm{RT}}{\overline{\mathrm{V}}} \ln \frac{\mathrm{e}}{\mathrm{e}_{\mathrm{o}}}
$$

where,

$\bar{V}$ is the partial molal volume of water $\left(18.015 \mathrm{~cm} \cdot{ }^{3}\right.$ mole $\left.\mathrm{e}^{-1}\right)$.

(See Appendices 1, 2, and 3 for energy-pressure conversions, definition of units, and equivalent relative vapor pressures for various solution concentrations.)

\section{Components of Water Potential}

There are a number of component forces affecting the water potential, the most important of which are:

Osmotic potential $\left(\psi_{-}\right)$: the osmotic component $(\pi)$ of the total water potential ( $\psi$ ) reduces the chemical free energy of a solution as a function of the presence of dissolved substances in the solution. Dissolved substances, such as salts, sugars, and other solutes, are either ionized in solution or have an asymmetrical distribution of surface electrical changes so that they attract the highly polar water molecules. The attractive forces of these oppositely charged ions and molecular surfaces are reduced by the high dielectric constant of water. The force of this attraction, resulting in neutralizing ion-dipole bonds, reduces the chemical-free energy or water potential of the solution below that of pure free water.

Matric potential $\left(\psi_{m}\right)$ : the matric component $(\mathrm{m})$ reduces the water potential as a function of capillary or colloidal adsorptive forces by soil particles, cellular colloids, and cell walls. In normal, nonsaline soils the energy status of water is more closely related to the thickness of the absorbed film of water on the soil particle than to any other factor. The force of adsorption between the matrix surface and the water molecules reduces the chemical free energy or water potential below that of pure free water.

Pressure potential $\left(\psi_{p}\right)$ : the pressure component (p) may raise or lower the water potential depending on whether the molecules are subjected to pressures above or below atmospheric pressure. Under either natural conditions or simulated conditions in the laboratory, only atmospheric positive pressures will be of concern. Under atmospheric pressure conditions, the effect of the pressure component on an open system, such as soil, is zero. Positive pressure against the vacuolar membrane and cell wall in plants (turgor pressure) resulting from hydrostatic forces of water will add free energy to the system, and the water potential will be increased. At wilting, the pressure component will approach, or reach, zero and will not affect water potential appreciably. 
In addition to these three principal components, the water potential is affected by temperature and gravitational forces. The water potential decreases as the temperature decreases because of a loss of heat (free energy) from the individual water molecules. Effects of gravity may be important to considerations of water movement over a considerable vertical distance, such as water columns in tall trees, but gravity can usually be neglected in studies of soils and most plants. Water potential is usually determined at the ambient temperature and then corrected back to $25^{\circ} \mathrm{C}$. (or the temperature of calibration under isothermal conditions) at normal atmospheric pressure, and over a very small vertical extent. The effect of temperature is eliminated by this adjustment. As previously stated, the influence of gravitational forces is usually negligible.

Under most conditions in the soil-plant system, the most important variables affecting water potential (other than temperature influences which must be corrected) are the osmotic, matric, and pressure potentials. Since the pressure component does not affect the soil water potential appreciably, an equation expressing the sum of the components affecting the total soil water potential can be written as:

$$
\psi=\psi_{\pi}+\psi_{\mathrm{m}}
$$

where:

$\psi$ is the total water potential;

subscript $\pi$ is the osmotic component; and, subscript $m$ is the matric component.

In the plant, an equivalent expression for the total plant water potential is:

$$
\psi=\psi_{\pi}+\psi_{\mathrm{m}}+\psi_{\mathrm{p}}
$$

where:

$\psi_{\mathrm{p}}$ is the pressure potential.

It is important to understand that equations (3) and (4) express water potential (a negative quantity) as the algebraic sum of osmotic potential (negative) matric potential (negative), and pressure potential (positive). Usually the matric potential is not considered a major component in the plant water potential, and there is a tendency to combine it with the osmotic potential. The distinction between these two components can become somewhat arbitrary, but there are recent convincing arguments that they are not strictly additive quantities (Salisbury and Ross 1969). More detailed discussion of the characteristics of the individual components of the water potential are beyond the scope of this paper, but they are presented elsewhere (Boyer 1967, Wiebe 1966, Wilson 1967, and Slatyer 1967).

When water potential gradients are established, there will be a tendency for water to diffuse from the region of higher free energy to a region of lower free energy. Thus, equilibrium will be favored even though true equilibrium may never be reached under natural conditions. The thermodynamic principles that explain the theory of water potential serve to adequately predict the direction, but not the rate, of either diffusion or energy transfer. Transfer rates are strongly dependent upon the nature and sources of resistances imposed on the diffusion pathway, but a thorough treatment of these principles is beyond the scope of this paper. The interested reader is referred to Slatyer (1967), Taylor and Cary (1965), Biggar and Taylor (1960), Letey (1968), and Briggs (1967). 


\section{METHODS OF MEASURING WATER POTENTIAL Nonpsychrometric Methods}

Several techniques are available for determining the water potential in the soilplant system, but some of them have a rather limited application; others are undesirable in view of recent advances in water relations technology. Techniques for measuring soil water potential that are still in wide use but of limited applicability include: tensiometers capable of measuring matric potential only between 0 and -1 bar; freezing point depression; electrical resistance units with a sensitive range for matric potential of -0.5 to -15 bars; and the pressure membrane or plate technique for inferring matric potential from water content. Of course, these techniques can be valuable depending upon the specific parameter of soil water being investigated, but inference of soil water potential from them can lead to considerable error. Of particular danger is the inference of water potential from soil water content. The relationships between free energy and water content are different for each kind of soil (and perhaps between samples of the same kind of soil), changes in temperature, and because of hysteresis. These techniques and their probable errors are discussed in detail by Taylor and others (1961) and Slatyer (1967).

Many techniques are based on direct measurements of plant water content still in wide use for evaluating the water status in plant tissue. Although Barrs (1968) believes there is some doubt concerning whether water content or water potential is the more important parameter affecting plant growth, there is little argument that water absorption, water transfer from cell to cell, and transpiration losses result from water potential gradients. This question is considered, together with a thorough analysis of methods of determination of water deficits in plant tissues, by Barrs (1968).

\section{The Thermocouple Psychrometer Method}

Spanner (Peitier) and Richards and Ogata (Wet-Loop) Psychrometers: In recent years considerable research has produced instrumentation capable of sensing the vapor pressure of water in a system. Equations (1) and (2) show that vapor pressure is a sensitive indicator of the water potential; most of the other component potentials also could be measured from vapor pressure. However, since the relative vapor pressure of soil water and plant tissue within the range of usual physiological interest ( 0 to -75 bars) lies very close to the saturated vapor pressure (95 to 100 percent), the method must be capable of detecting very small changes in vapor pressure. Spanner (1951) first demonstrated that sufficiently sensitive measurements of the relative vapor pressure of water in this very narrow range of interest can be made with small sensitive thermocouples. This led to a great deal of research on the development and use of thermocouple psychrometers for measurements of water potential. This method offers great sensitivity and accuracy and can be used either in the laboratory with very small samples or in the field over extended periods.

The Spanner psychrometer consists of a small thermocouple sealed either in a small chamber or other housing (figure 1). The thermocouple is usually constructed of 0.001inch diameter chromel-constantan (although Spanner originally used bismuth-bismuth-5 percent tin) wires with a small welded bead at the junction; these thermocouple wires are attached to copper lead wires connected to a galvanometer, recorder, or a microvoltmeter. In laboratory models the thermocouple is suspended directly over a soil or leaf sample all of which are inside a sealed chamber, and the chamber is then immersed in a water bath to maintain a constant temperature. Under these isothermal conditions, the vapor pressure of the atmosphere above the sample and around the thermocouple will come into equilibrium with the water potential of the sample, usually within a few hours. After vapor and temperature equilibria are achieved, the water potential of the sample can be determined. A small amount of water is condensed on the thermocouple junction 
Figure 1. The Spanner

(Peltier) thermocouple

psychrometer and a

psychrometer chomber

are shown with the soil

sample. The entire

assembly is sealed and

immersed in a water bath

to maintain constant

temperature.

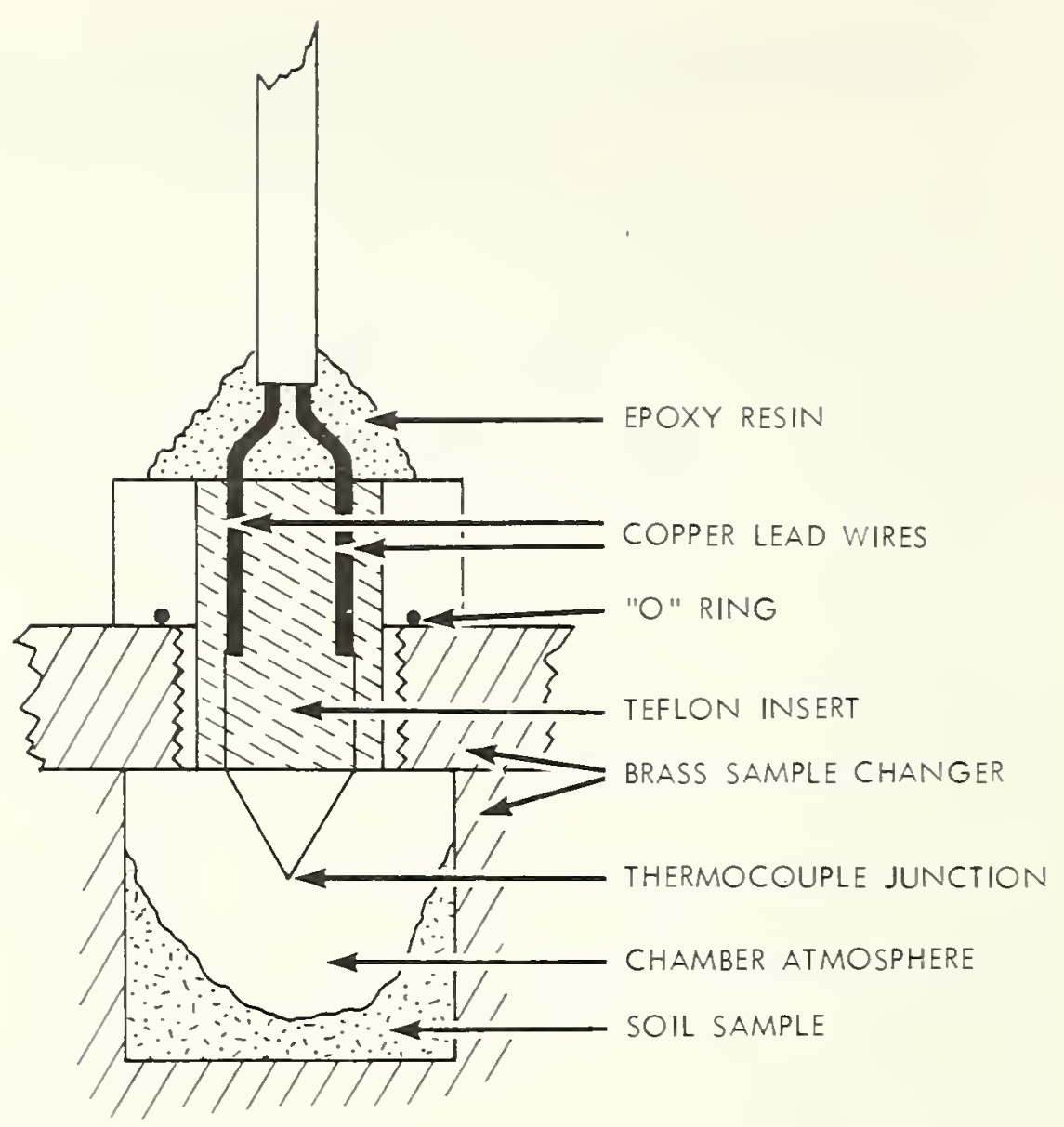

by passing a small electric current through the junction for a short time in a direction which causes it to cool below the dew point of the atmosphere (Peltier effect). After this cooling, the current is imnediately stopped, allowing the condensation to evaporate back to the atmosphere in the chamber. The rate of evaporation is a function of the vapor pressure in the chamber, hence of the water potential of the sample. The evaporation cools the junction as a function of the vapor pressure, and the difference in temperature between the sensing junction and the reference junctions causes a minute voltage output from the thermocouple. The magnitude of this voltage output is also a function of the sample water potential, and is recorded with a microvoltmeter.

Richards and Ogata (1958) suggested a modification of the Spanner psychrometer, consisting of a small silver ring attached to the ends of the chromel-constantan thermocouple wires (figure 2). A small water drop (3-5 $\mu$ liter) is placed on the ring, and then is sealed in the chamber containing the sample. Readings are made when the rate of evaporation from the water droplet reaches a steady value, and hence when the temperature depression of the thermocouple is constant. The primary difference between the Spanner and the Richards and Ogata types of psychrometers is that the Spanner thermocouple permits measurements of both dry and wet-bulb temperatures, whereas with the Richards and Ogata psychrometer the dry bulb temperature can only be inferred from bath temperature.

Considerable attention has been given in recent years to the relative performance of these two psychrometers for measuring water potentials of soil and plant tissue. Rawlins (1966) rigorously reviewed the performances of these two psychrometers and suggested sources of possible errors and design criteria for reducing the magnitude of inaccuracies of water potential determinations. Barrs (1965) found that because of the permanently wet junction in the Richards and Ogata psychrometer, the observed temperature depression was between the reference junction temperature and wet bulb temperature, and this led to low estimates of water potential. Zollinger and others (1966) 
Figure 2. - The Richards and Ogata thermocouple psychrometer showing the sizver ring used to support the water droplet.

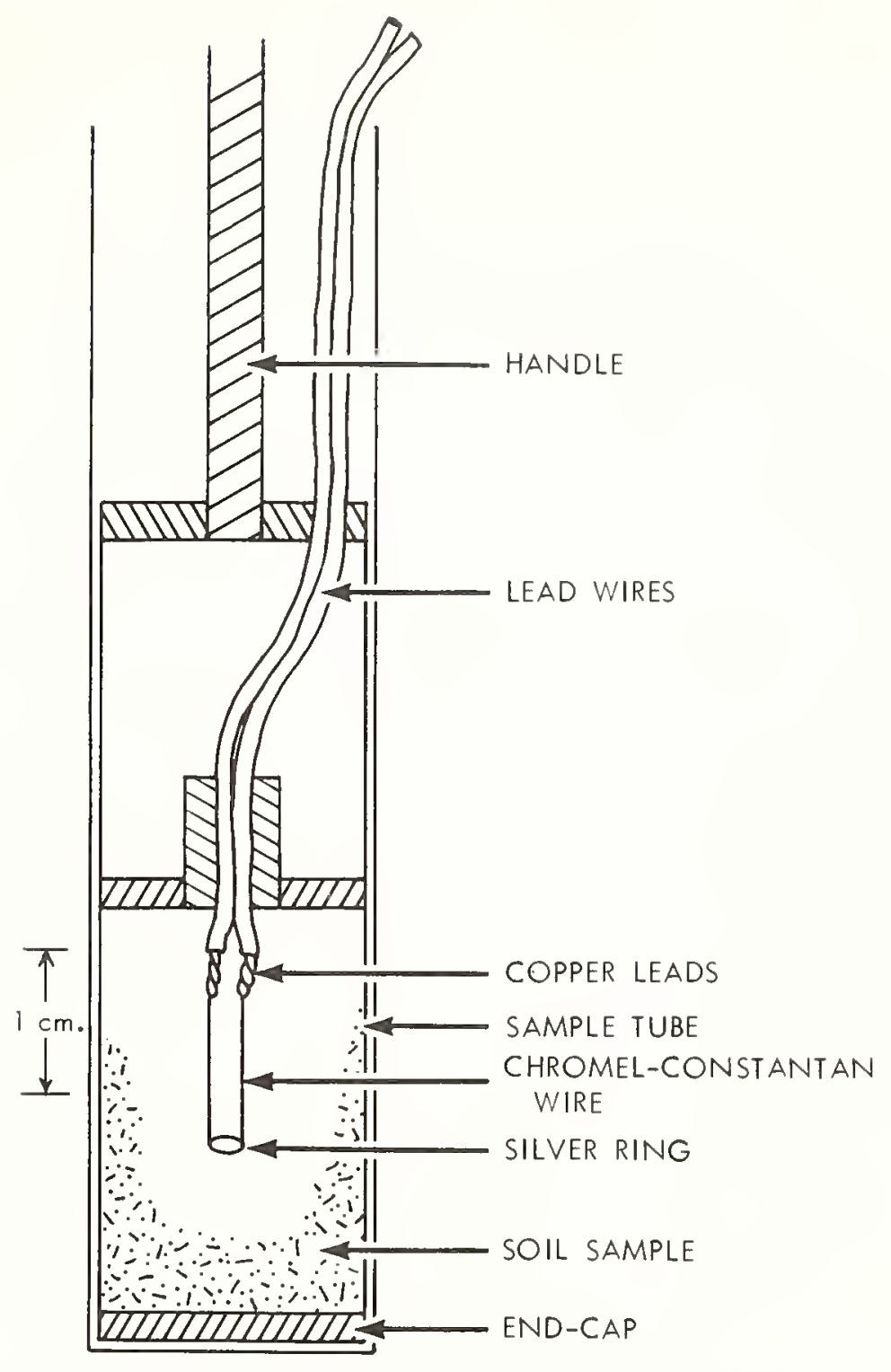

also found greater errors in estimates of water potential with the Richards and Ogata (wet-loop) psychrometer. Either psychrometer will cause the true water potential to be somewhat disturbed, but the wet-loop psychrometer adds vapor to the system resulting in high estimates of water potential. The small amount of vapor withdrawn from the atmosphere with the Spanner thermocouple will have a negligible influence in most cases (Zollinger and others 1966).

A number of modifications and advances in techniques have been suggested for both types of psychrometers; but even with these advances, the Spanner psychrometer has come into more general use. The theory of the Spanner psychrometer and design criteria for its construction, together with sources of error in its use, have been thoroughly investigated (Rawlins 1966; Peck 1968, 1969; Dalton and Rawlins 1968; and Barrs 1968). Special techniques and precautions to follow during construction are discussed by Merrill and others (1968), Campbell and others (1968), and Wiebe (1970). Some of these points are discussed below.

One of the most useful adaptations for laboratory analysis of leaf and soil water potentials is the rapid sample changer suggested for use with Peltier psychrometers by Campbell and others (1966). I have used a modification of this sample changer for several years, and have obtained very satisfactory determinations of water potential. The sample changer consists of six chambers lined with small $\left(0.75 \mathrm{~cm} .{ }^{3}\right)$ Teflon cups in which the leaf or soil samples are placed. The same Peltier thermocouple is used to 
measure all six samples by rotating the sample changer after each measurement. This technique has the advantage of being simple to use, easy to calibrate, and the same thermocouple is used to make all measurements. Also, one or more of the six sample chambers may be used as calibration chambers by saturating a filter paper lining inside the Teflon cup with standard KCl solutions.

Measurements of water potential in situ: The adaptability of psychrometers for use under field conditions is the most important and significant improvement resulting from research in psychrometric technology. These recent contributions have opened a whole new frontier in soil-plant water relations and for the first time enable the researcher to gain a quantitative and true measure of the water status in natural systems. Because thermocouple psychrometers have such a high degree of sensitivity to temperature fluctuations, their use in natural systems, which are subject to large ambient temperature changes, has evolved only recently. Rawlins and Dalton (1967) explained that there are at least four ways in which changes in ambient temperature can cause changes in thermocouple output. First, the relationship between water potential and vapor pressure is temperature dependent, as shown in equation (2). Second, the relationship between wetbulb depression and internal vapor pressure in the chamber is temperature dependent. Changes in psychrometer sensitivity due to temperature shifts can be explained by the temperature dependence of thermal conductivity of the chamber air; water vapor diffusivity of the chamber air; and the heat of vaporization of water. Third, changes in ambient temperature produce slight temperature gradients between the sensing junction and reference junctions in the thermocouple (figure 1). Fourth, an increasing temperature will result in an increased water-vapor-holding capacity within the sample chamber, and the relative humidity of the air will decrease until vapor equilibrium is again achieved. If the sample chamber was sealed, the resulting error would be about 1 bar per $0.01^{\circ} \mathrm{C}$. at $25^{\circ} \mathrm{C}$.; but if the chamber was open or porous to free vapor exchange, the error would be considerably less.

In an attempt to meet the requirements of ambient temperature fluctuations and the resistance to vapor flow, Rawlins and Dalton (1967) constructed a psychrometer designed for use directly in the soil mass (figure 3). Surrounding the thermocouple was a ceramic bulb through which vapor exchange must occur between the soil and the internal atmosphere. They concluded that this instrument estimates the soil water potential within a few tenths of a bar. Rawlins and others (1968) used this same psychrometer for in situ measurements of soil water potential in a greenhouse study on water relations of a pepper plant.

In a somewhat unique approach to soil-plant water relations, wiebe and others (1970) used a variation of the Rawlins and Dalton pyschrometer (figure 4) consisting of a small ceramic cup surrounding the thermocouple; this system measured the water potential gradients in trees from the soil, up through the trunk, and through the branches. These instruments were buried in the soil at various depths, and were installed about $1 \mathrm{~cm}$. under the cambium in the tree trunk. Diurnal fluctuations in the water potential gradient were recorded for periods of up to 6 weeks. The psychrometers had to be moved periodically in some species because of wood decay and resin exudation into the cavity.

Hoffman and Splinter (1968a, 1968b) used a psychrometer design similar to that of the Rawlins and Dalton model but without the ceramic cup. The thermocouple was centered in a small Teflon cup open at the bottom end, and was then buried in the soil or mounted on a tobacco leaf surface with an adhesive. This design provides a psychrometer which has a geometry that is identical for both calibration and measurement of soil and leaf water potential. However, there is the danger of the exposed thermocouple becoming damaged or bent after placing the psychrometer in the soil. Lang (1968) used a Spanner 

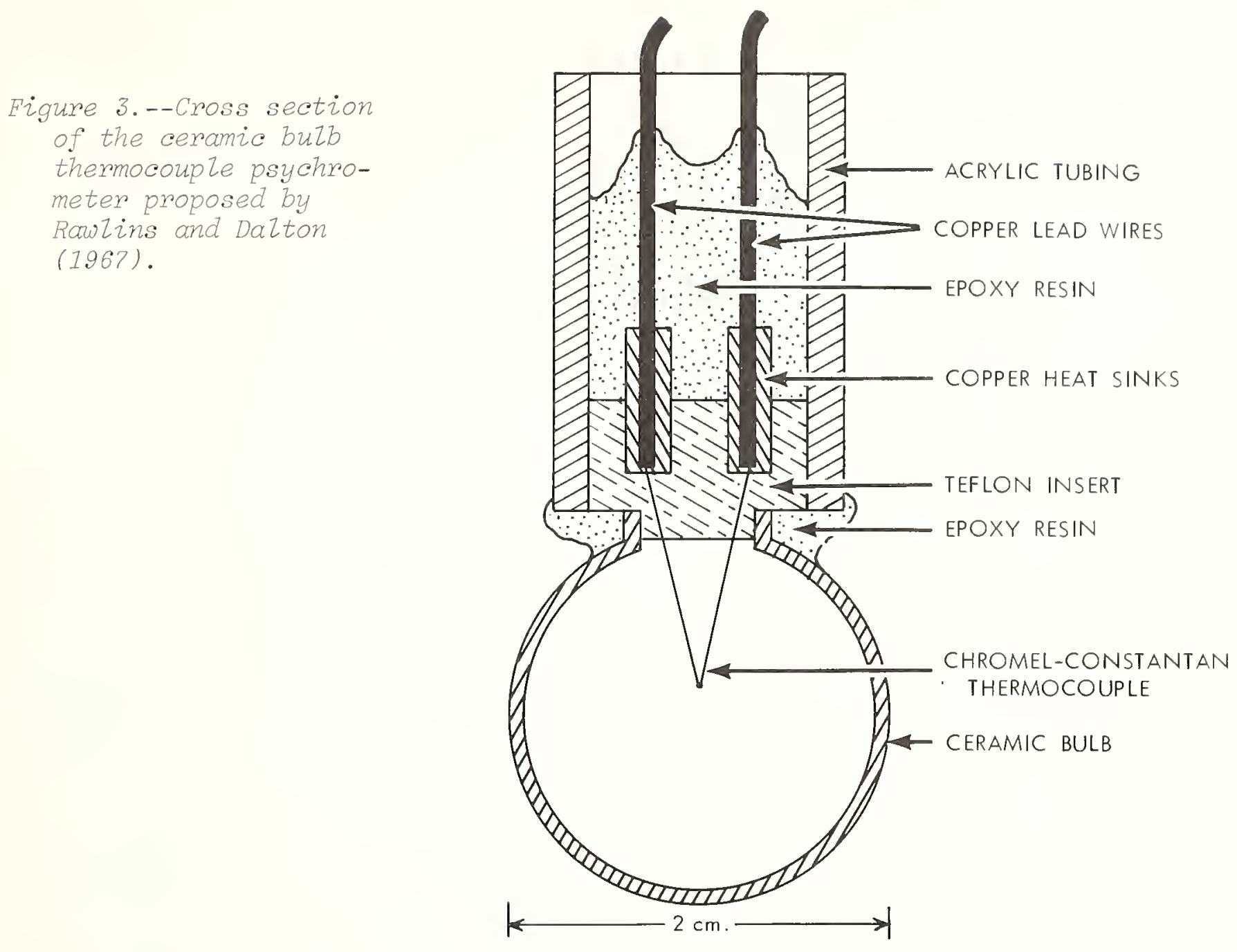

psychrometer encased in a wire gauze cage of 100 -mesh stainless steel for measurements of soil water potential. The wire cage provides a protective covering for the thermocouple, and thus would be superior to the model used by Hoffman and Splinter (1968a). However, Lang's psychrometer was especially constructed to be inserted into the wire cage sometime after the cage was buried in the soil. This approach may lead to drying of the soil immediately adjacent to the wire cage, and it may also offer a considerable degree of difficulty in properly inserting the exposed psychrometer into an access hole in the soil.

The most important recent development for in situ measurements of leaf water potential is the double junction thermocouple psychrometer (Wiebe 1970). This instrument consists of two chromel-constantan thermocouple junctions and three reference junctions attached within a Teflon insert. Three copper leads are joined within the Teflon insert by the two thermocouple junctions; the chromel wires of both junctions are attached to two of the copper leads, and the constantan wires of both junctions are attached to the third copper lead. The two sensing junctions produce opposing e.m.f.'s so that the cooling current is passed through one junction and the output is read from the other. The output is then proportional to the temperature difference between both sensing junctions, and since both are in the same thermal environment, one junction compensates for rapid temperature changes which may easily occur on an attached leaf surface. This entire assembly can be placed in a Teflon cup open at the bottom end, and mounted on a leaf surface similar to the method of Hoffman and Splinter (1968a, and 1968b). 
Figure 4.--Cross section of the ceramic cup thermocouple psychrometer used by Wiebe and others (1970).

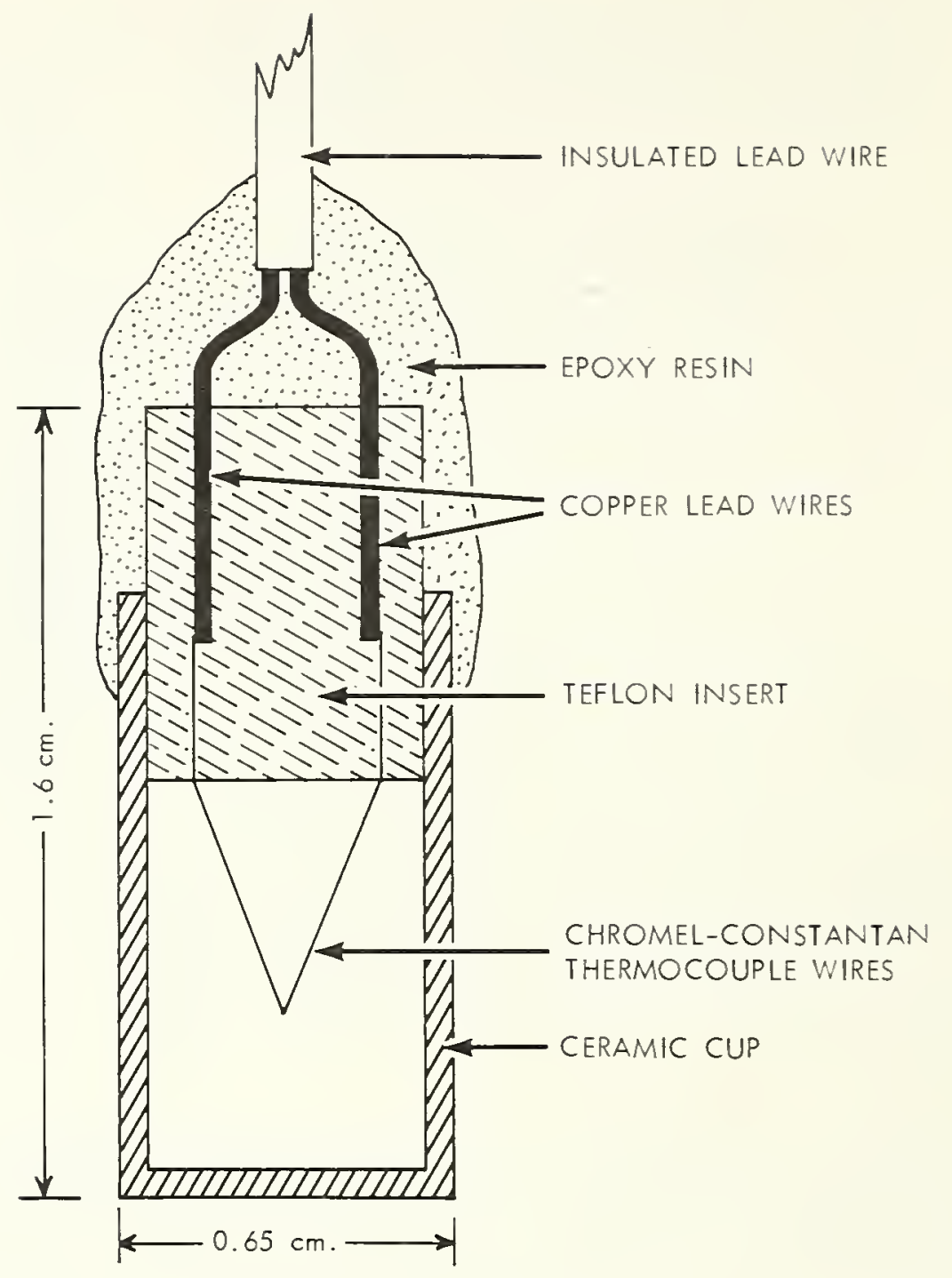

\section{IMPROVED DESIGN CRITERIA FOR THERMOCOUPLE PSYCHROMETERS Considerations of Instrument Design}

The thermocouple psychrometers described by Rawlins and Dalton (1967) and Wiebe and others (1970) would appear to offer excellent opportunities for the measurement of soil and plant (tree trunks) water potentials under natural conditions. However, the question of resistance offered by the ceramic cup to the transfer of water, particularly water vapor, has not been adequately investigated. Rawlins and Dalton (1967) concluded that in order to maintain a water potential difference of less than 0.1 bar between the chamber and the soil, the conductivity of the ceramic wall must be at least $4 \mu \mathrm{g}$. $\mathrm{cm} .^{-2}$ bar hour for each degree per hour change in temperature. They indicated that the saturated conductivity of porous ceramic is about six orders of magnitude greater than this, and that resistance to water transfer was not limiting. However, they did not discuss the implications resulting when liquid contact between the soil particles and the ccramic cup is broken, wherein water transfer between the chamber and the soil will occur only through vapor exchange. If a resistance to vapor exchange between the ceramic chamber and the surrounding medium results, significant errors in estimates of water potential will result.

The primary function of the ceramic bulb or the ceramic cup is to maintain a fixed dimension in the soil, and to offer protection for the thermocouple. If these same 
Figure 5.--The screen thermocouple psychrometer.

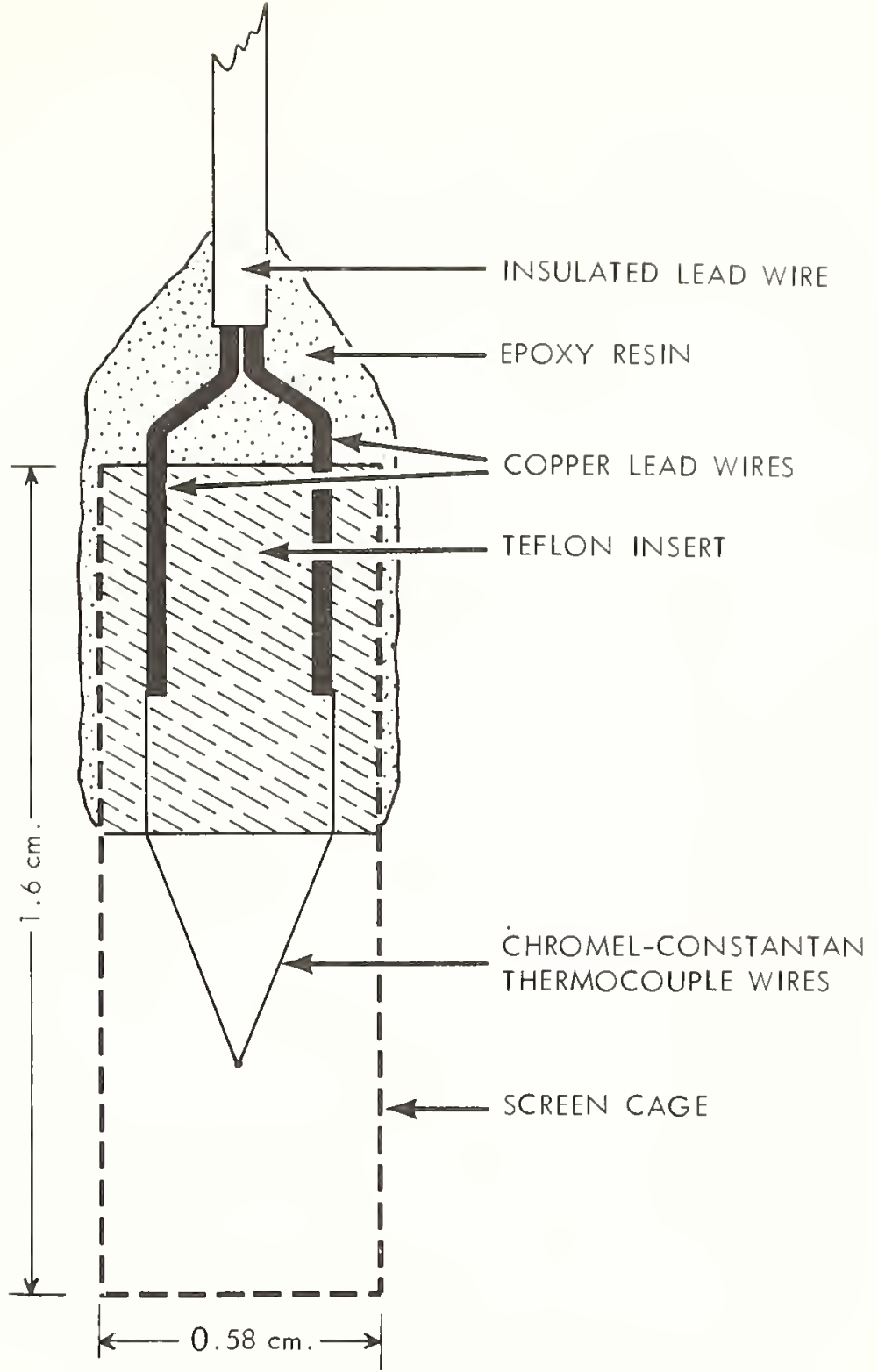

criteria could be accomplished without imposing a resistance to vapor exchange, at least the accuracy of the instrument would be improved; this improvement would result from reduction of a lag in response to a change in water potential where water transfer is in the vapor phase. Even though a rigid ceramic cup imposes a substantial lag to vapor exchange, a fine mesh noncorrosive screen cup appears to meet the essential criteria quite well, and permits heat and vapor exchange with negligible resistance. These features were incorporated into a psychrometer built by the author, quite independent of Lang's (1968) instrument, and considerably simpler in design and of greater versatility. This psychrometer somewhat resembles the instrument used by Wiebe and others (1970), except that the ceramic cup was replaced with a screen cup. A large number of these psychrometers that were used over the last 2 years in the laboratory at Logan for measurements of soil water potential have proven this design to be stable and reliable.

\section{Construction and Equipment}

The essential parts of the pyschrometer (figure 5) consist of a screen cup constructed of fine-mesh stainless-steel wire and attached to a Teflon insert. Within this insert the copper lead wires are attached to the thermocouple. After cutting the Teflon insert (see Appendix 4 for sources of supply) to the proper length $(0.475 \mathrm{~cm}$. diameter rod cut to $0.635 \mathrm{~cm}$.), make two holes approximately $0.025 \mathrm{~cm}$. in diameter through the long axis of the Teflon with a fine dissecting needle. Then insert the chromel 
and constantan thermocouple wires $(0.0025 \mathrm{~cm}$. diameter) through the holes from the bottom side of the Teflon insert, from which about a $4-\mathrm{cm}$. length of each wire is allowed to protrude. About $0.5 \mathrm{~cm}$. of the ends of the copper lead wires (Beldon $\# 8640$, 26 gage) are scraped clean of all insulation and inserted into the holes from the top side of the Teflon insert. The positive copper lead is tightly wedged into the hole with the chromel wire and the negative lead with the constantan wire. This provides a tight contact between the copper and thermocouple wires. An alternative method of attaching the thermocouple wires to the copper lead wires is to solder the chromel wire to the positive copper lead and the constantan to the negative copper lead. A high grade of silver solder should be used.

The chromel and constantan wires protruding from the bottom of the Teflon insert are twisted together with an "L"-shaped piece of wire (26 gauge, $3 \mathrm{~cm}$. 1ong with an "L" bend of about $3 \mathrm{~mm}$.). The "L"-shaped tool is held between the thumb and forefinger, and is twirled slowly around the two thermocouple wires, twisting the two wires tightly together. The wires are twisted together until their junction is about $3 \mathrm{~mm}$. away from the Teflon, then the "L"-shaped tool is inserted between the chromel and constantan wires and the junction pulled out to exactly $4 \mathrm{~mm}$. from the Teflon insert. This tightens the junction and provides a uniform length to the thermocouple assembly. The excess twisted wire can be cut away with a scissors, leaving about $3 \mathrm{~mm}$. of twisted wire below the junction. The thermocouple is now ready to be welded or soldered; rowever, welding is preferred because soldered thermocouples tend to age rather quickly and do not have a linear response throughout the range of vapor pressures of interest (Campbell and others 1968).

Welding can be accomplished as suggested by Campbell and others (1968). Also, a somewhat simplified technique may be used wherein the negative lead from the arc-welder is attached to the ends of both copper leads from the thermocouple. (A diagram of the electrical circuit used in my arc-welder is given in Appendix 5.) The positive lead from the arc-welder is attached to a sharpened graphite rod (4H graphite lead), which is used to provide the arc for welding. Welding is accomplished by touching the graphite rod to the end of the twisted thermocouple wires. The twisted thermocouple wires should be welded slowly (by adjusting the voltage output from the welder) at first, building up a bead of fused metal. Welding should continue until about one twist remains beyond the beaded junction. The bead should be about three times the diameter of the thermocouple wires, although the most successful psychrometers will have as large a bead as possible. The largest junction diameter possible with this technique appears to be about five times the wire diameter (Campbell and others 1968). The best results will be achieved if the entire thermocouple assembly process is accomplished with the aid of a binocular scope with a $7 X$ to lox magnification.

A legitimate argument can be raised concerning the advisability of welding thermocouples in normal air rather than in nitrogen gas or oil. In the presence of relatively high oxygen partial pressures, the welding process leaves a deposit of oxidized material on the thermocouple junction. This deposit may influence thermocouple output and psychrometer calibration. A number of workers have used some rather elaborate devices to hold the thermocouples in place during construction and welding. In general, a $\mathrm{jig}$ is used to hold the thermocouple securely, which is then placed in a sealed enclosure and flushed with nitrogen gas (Lopushinsky and Klock 1970). A'somewhat simplified yet equally effective method is to perform the welding operation in a small pool of lightweight optically clear oil such as 10 -weight motor oil or even comnercial salad oil.l The thermocouple assembly is completely immersed in a petri dish of oil, and the junction is welded by touching the graphite rod to the junction until the bead is formed. In this manner a greater degree of control can be exercised over the rate of welding, and incidences of overheating and breaking the junction are much less frequent than when welding is done in a gas. The thermocouple should be dipped into acetone and slightly agitated to remove all traces of oil.

\footnotetext{
${ }^{l}$ Eric Campbel1, personal communication, 1969.
} 
The screen cup is made from 200-mesh stainless steel screen with an opening width of $0.0074 \mathrm{~cm}$. (74 microns). Each screen cup is made by cutting pieces of screen 1.8 $\mathrm{cm}^{2}$ and then rolling the screen over a short piece of $0.475 \mathrm{~cm}$. diameter Teflon rod. The screen overlaps slightly and is then soldered with a high grade silver solder along the seam. The outside diameter of the screen cup is $0.581 \mathrm{~cm}$, and the inside diameter is $0.475 \mathrm{~cm}$., which facilitates a snug fit over the Teflon insert. A circular disk of $0.475 \mathrm{~cm}$. diameter screen is silver-soldered on one end of the screen to close the tube. After soldering, the screen is boiled in distilled water, followed by a rinse in acetone, and rinsed again in distilled water to remove all traces of solder flux. The screen is then slipped all the way up on the Teflon insert and permanently fixed in place with epoxy resin. The inside volume within which the thermocouple is housed is $0.188 \mathrm{~cm} \cdot{ }^{3}$.

\section{Calibration and Measurement Procedures}

Calibration of these instruments is achieved by mounting the complete psychrometer in a small test tube lined with filter paper moistened with various KC solutions (see Appendix 3 for water potentials of various molal solutions). The filter paper lining should include a disk at the bottom of the test tube $(1.1 \mathrm{~cm}$. by $9.9 \mathrm{~cm}$. inside dimensions) together with a strip of filter paper around the inside circumference of the tube; the filter paper should extend up the side walls about 1 inch from the bottom (Whatman \#1 chromatography paper). About 6 to 8 drops of solution are sufficient to fully moisten the filter paper. The psychrometer is lowered into the test tube until the screen cup containing the thermocouple is below the filter paper lining, and is then sealed with a rubber stopper through which the copper lead wires extend. The stopper and lead wires can be coated with vacuum grease or RTV to insure a tight seal.

The test tubes containing the psychrometers are then completely immersed into a constant temperature bath at $25^{\circ} \mathrm{C}$. Usually temperature and vapor equilibrium can be achieved within 30 minutes (figure 6), but at least 2 hours should be allowed to eliminate all temperature gradients. Because the thermocouple psychrometers are very temperature sensitive, calibration is repeated at several temperatures between $10^{\circ} \mathrm{C}$. and $35^{\circ} \mathrm{C}$. However, it has been found (Wiebe and others 1970) that chromel-constantan psychrometers follow a rather simple relation between e.m.f. output vs. temperature. This relation is expressed by:

$$
C F=\frac{1}{0.027 T+0.325}
$$

where CF is a correction factor to be multiplied by the output in $\mu v$ at the known psychrometer temperature, $\mathrm{T}\left({ }^{\circ} \mathrm{C}\right.$. $)$. Equation (5) permits calibrations to be made at $25^{\circ} \mathrm{C}$., from which water potentials at any other temperature can be determined. In some cases, however, individual thermocouple differences may cause the temperature response to deviate slightly from the theoretical value expressed by equation (5) (Wiebe 1970). Therefore, it is recommended that thermocouple psychrometers be calibrated at several temperatures as described above.

To obtain actual psychrometer readings, two basic instruments are used: (1) a sensitive microvoltmeter; and (2) a special circuit used for cooling the thermocouple wet junction. The most commonly used voltmeters include a Hewlett-Packard Model 419A, or the Keithley Model 155 (figure 7), both of which are portable and permit measurements to the nearest $0.1 \mu \mathrm{v}$. In addition to these, even more sensitive recording instruments are often used, such as strip-chart recorders with an amplifier and more sensitive microvoltmeters (Appendix 4). A diagram of the cooling circuit ("switchbox") is shown in Appendix 6, together with a list of the component parts. The switchbox (figure 7) is mounted in an insulated aluminum box to prevent rapid temperature fluctuations. The switchbox permits a direct connection of the thermocouple to either the voltmeter or the cooling circuit. 
Figure 6.--The influence of temperature gradients between the

thermocouple reference junctions and sensing junction. At temperature equizibrium thermocouple output is zero.

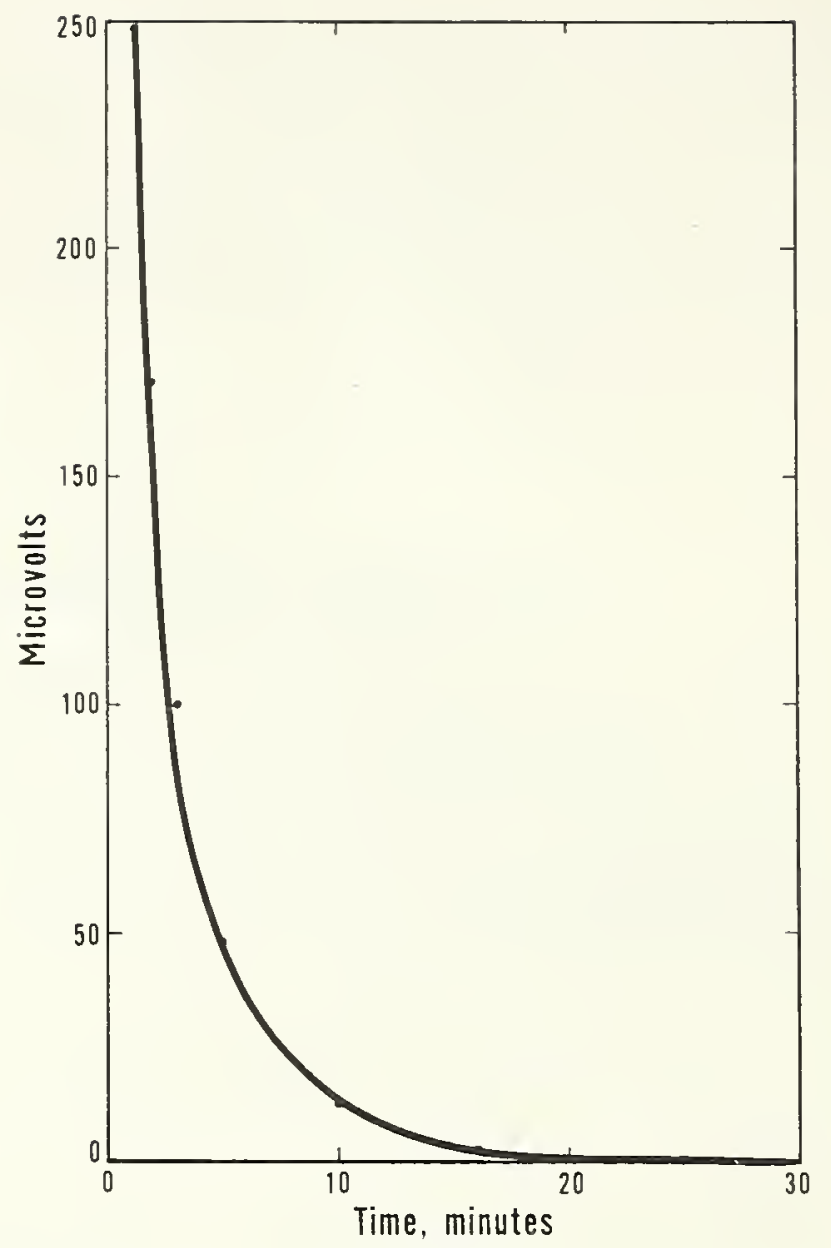

Since at temperature equilibrium (no temperature gradients between the sample and the psychrometer) the two reference junctions of the psychrometer are at the same temperature as the sensing junction, the e.m.f. output of the thermocouple is zero. When the thermocouple output is switched via the switchbox directly through the voltmeter ("read" position), the voltmeter is adjusted to "zero" or some other convenient position with the "zero-adjust" knob on the switchbox. Then the thermocouple is immediately switched to the cooling position for 15 seconds, which cools the sensing junction with a $5 \mathrm{ma}$. current. After 15 seconds, the thermocouple is immediately switched back to the "read" position, and the e.m.f. deflection is read on the voltmeter. The difference stated in $\mu v$ between the e.m.f. prior to cooling and immediately after cooling (maximum deflection) is the output for that particular water potential. This subtraction of the e.m.f. before cooling from the e.m.f. after cooling corrects for temperature differences between the sensing junction and reference junction, and also cancels any parasitic e.m.f.'s resulting from temperature differences between the various junctions in the thermocouple circuit. Furthermore, this subtraction reduces the need for thermal grounding normally required at junctions and terminals in the circuit during low voltage measurements (Rawlins and Dalton 1967).

The circuit diagram for the switchbox in Appendix 6 provides for the functions of "read," "zero," "cool," "heat," and "voltage check." The "heat" position is the reverse of the "cool" position and provides a slight heating current which can be used to quickly dry residual water from the thermocouple junction if needed. The "voltage check" position measures the internal voltage of the switchbox, and is used only with a recorder and amplifier in the system. The circuit shown in Appendix 6 has an internal voltage output of about $10 \mu \mathrm{v}$ which can be used to calibrate the scale on a linear recorder. All solder junctions in the switchbox should be made with thermal-free solder, and binding posts should be gold-plated to reduce parasitic e.m.f.'s at the terminal connections. 
Figure 7.-A commonly used microvoltmeter (Keithley mode 1 155) and a switchbox used for measuring psychrometer output.

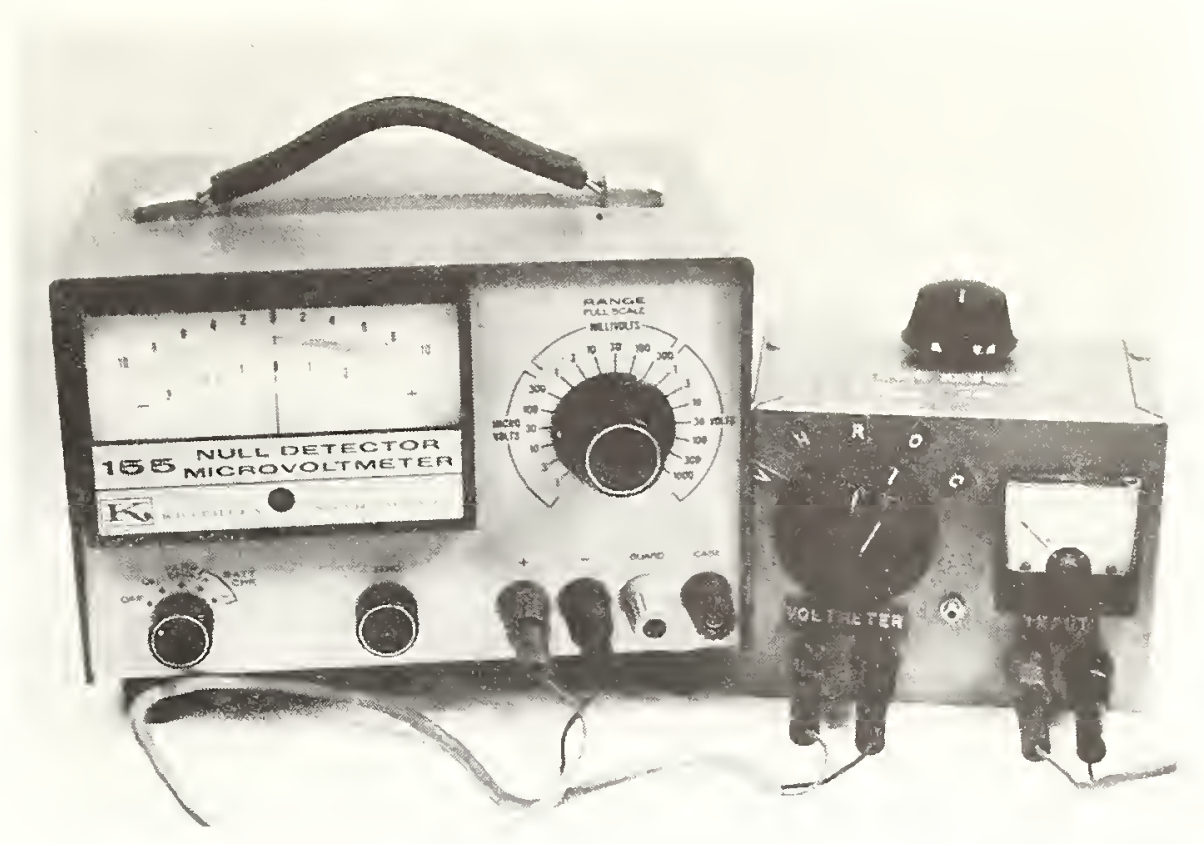

The $\mu \mathrm{V}$ output of the thermocouple for each KCl standard solution can be plotted as a function of water potential to give a calibration curve for each psychrometer (figure 8). It can be seen from the curve in figure 8 that thermocouple output varies about $0.5 \mu \mathrm{v} \mathrm{bar}^{-1}$ on the lower portion of the curve (below -40 bars) but decreases at lower water potentials. If the cooling time were extended beyond 15 seconds (to about 30 seconds), the linearity of the curve would be extended to lower water potentials (more negative), and the usable range of the psychrometer would be expanded to near -100 bars. However, even when using a 60 -second cooling time there appears to be a lower limit between -75 and -100 bars for these psychrometers. This lower limit for chromelconstantan thermocouples results because the Peltier effect is a somewhat inefficient cooling method, allowing a temperature depression of only about $0.6^{\circ} \mathrm{C}$. (Rawlins ${ }^{2}$ ).

Recalibration of the psychrometer should be performed after each extended period of use. Calibration points have been observed to change by $\pm 1 \mu \mathrm{v}$ over a period of 3 months, indicating that errors as great as 3 bars can result. The thermocouple junction will age somewhat due to corrosion, and adherence of foreign matter to the junction will also contribute to a change in the calibration. I have used several exceptionally well made psychrometers here at Logan that showed no sign of calibration drift even after 3 months of use. However, after each use of the psychrometer it is strongly recommended that a fairly vigorous cleaning routine be followed. For instance, I use the following procedure for routine cleaning:

1. Thoroughly wash the psychrometer in tap water to remove soil or other particles from the screen cup.

2. Then rinse in distilled water.

3. Boil for 10 minutes in distilled water.

4. Rinse in acetone.

5. Rinse in warm distilled water, let dry.

\footnotetext{
${ }^{2}$ S.L. Rawlins, personal communication, 1970.
} 


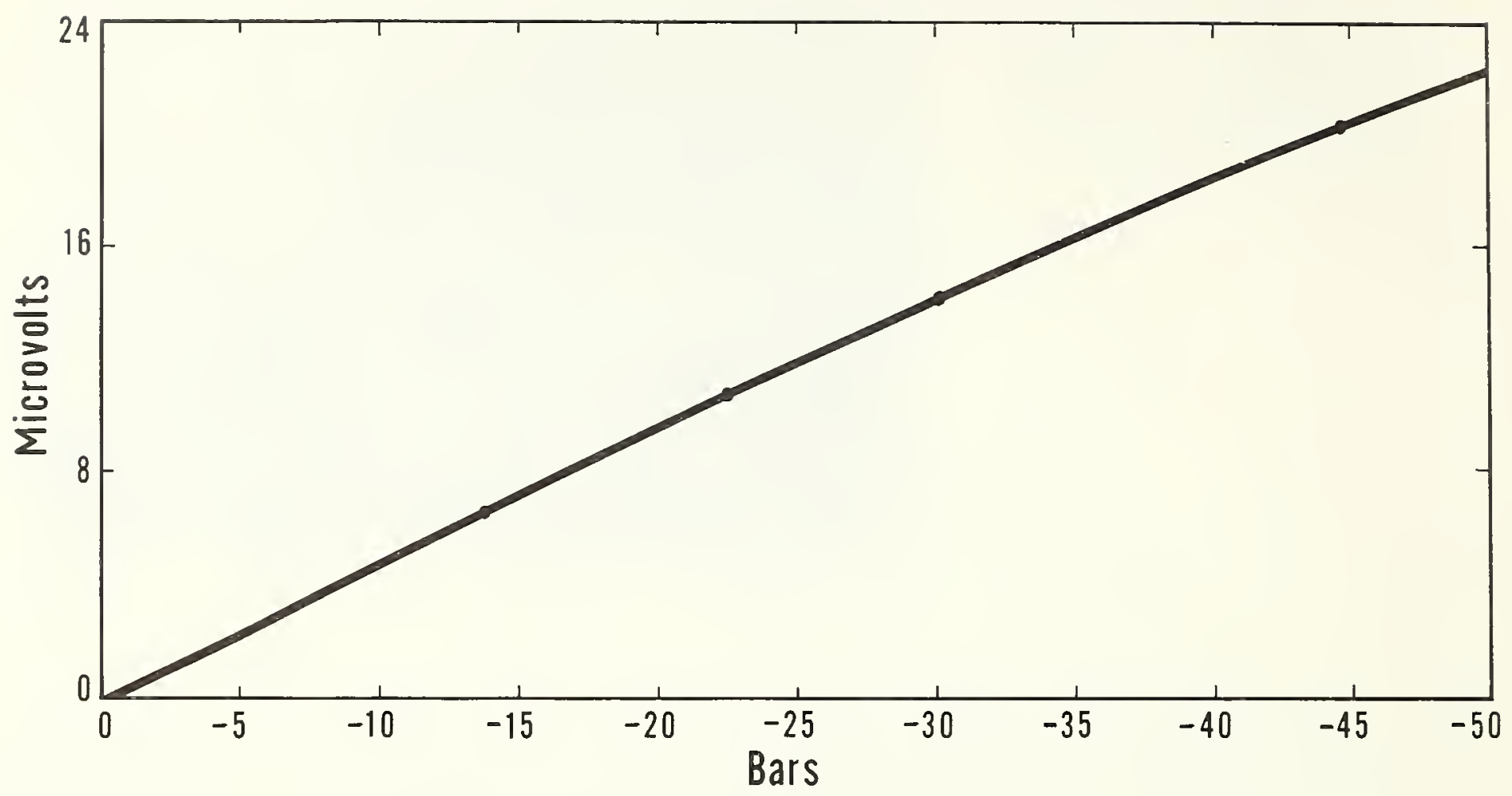

Figure 8.--Calibration curve for a chromel-constantan thermocouple psychrometer (output in $\mu v$ vs. osmotic potential of $\mathrm{KCl}$ solutions in bars) at $25^{\circ} \mathrm{C}$.

\section{Psychrometer Response to Changing Water Potentials}

If the screen psychrometer is to give accurate estimates of water potential, it should offer a negligible resistance to vapor and heat flux. To determine the magnitude of psychrometer lag in response to actual water potential, laboratory experiments were conducted in which the response of the screen psychrometers, ceramic cup psychrometers, and bare unshielded psychrometers were compared. The ceramic cup psychrometers used were of the same design as shown in figure 4 (Wiebe and others 1970), and the unshielded psychrometers were constructed as described above, except that the screen cup was not used. The exposed thermocouple was assumed to offer no resistance to vapor transfer, hence to yield accurate estimates of water potential.

In an attempt to determine the relative magnitude of the resistance imposed by various psychrometers to the transfer of water vapor, psychrometer response to various equilibrium vapor pressures was measured under isothermal conditions. The bare unshielded, screen, and ceramic cup psychrometers were sealed in test tubes containing standard KCl solutions of known vapor pressures at $25^{\circ} \mathrm{C}$. Summarized in figure 9 are the relative magnitudes of psychrometer response with time, and the length of time required for vapor equilibrium in a $0.3 \mathrm{molal}(\mathrm{m}) \mathrm{KC}$ solution. Time in minutes began when the psychrometers were placed in the water bath;temperature equilibrium as measured by thermocouple output was achieved within 20 minutes for all the psychrometers. However, vapor pressure equilibrium required a longer period of time for both the screen and ceramic cup psychrometers. The unshielded psychrometers reached vapor equilibrium at about the same time that temperature equilibrium was reached (20 minutes). The screen psychrometers reached vapor equilibrium some 13 minutes later, but the ceramic cup psychrometers did not reach equilibrium until about $2-1 / 2$ hours later.

From the data in figure 9 it is quite apparent that the ceramic cup psychrometers offer a far greater resistance and lag to vapor exchange than do the screen psychrometers. It is interesting to observe that the screen does offer a relatively small 


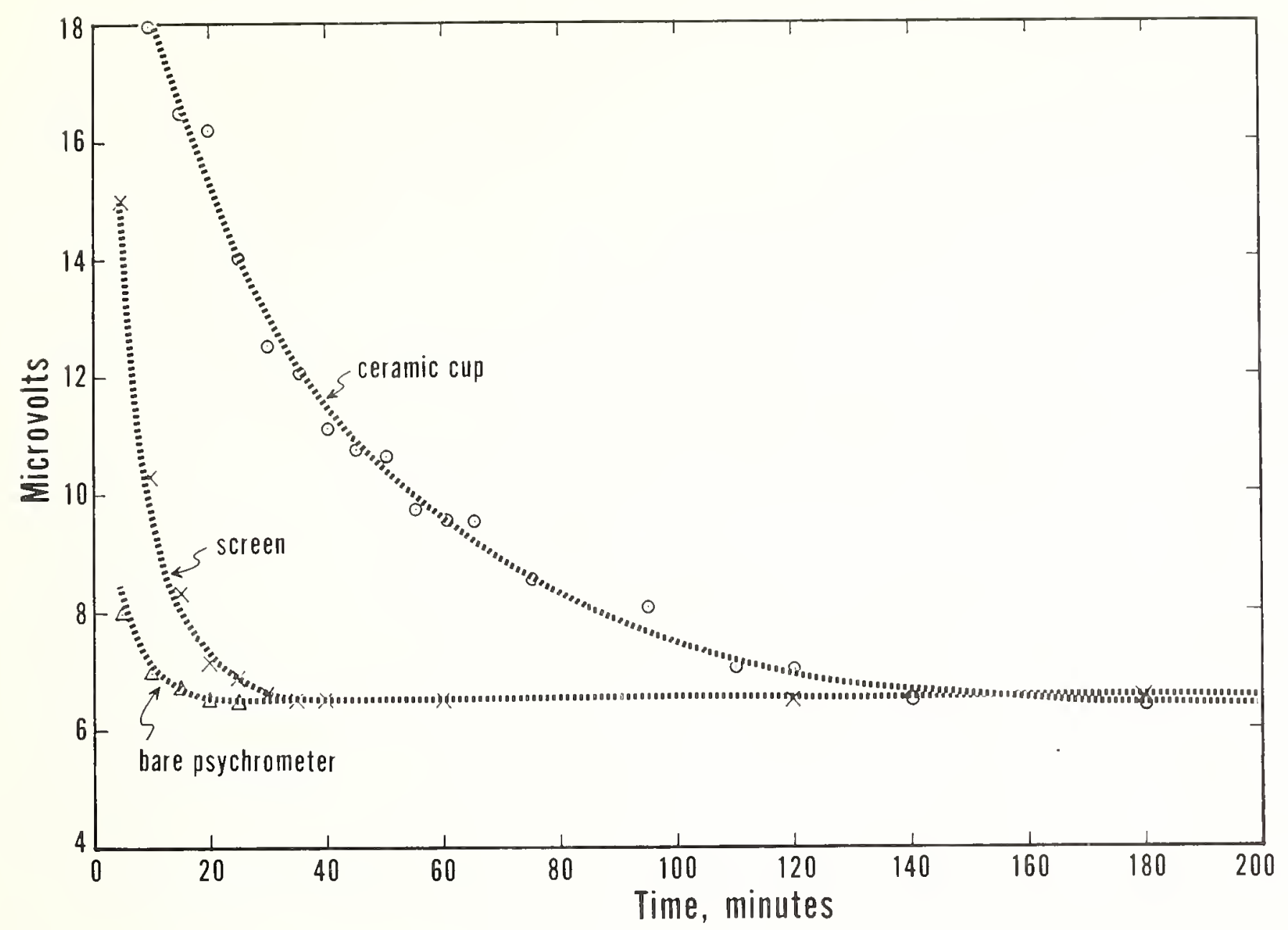

Eigure 9.--Lag in response of thermocouple psychrometers to vapor equilibrium over a 0.3 $m K C l$ solution at $25^{\circ} \mathrm{C}$. Note the equilibrium time required for the screen and ceramic cup psychrometers.

resistance to vapor transfer, but this appears to be negligible and may even be reduced by use of a larger mesh screen. In standard $\mathrm{KC}$ s solutions, vapor equilibrium for the three psychrometers was achieved somewhat sooner in solutions having a lower water potential because of the slightly reduced water potential gradient between the solutions and the psychrometers. However, the relative magnitudes of $1 \mathrm{ag}$, as shown in figure 9 for $0.3 \mathrm{~m} \mathrm{KCl,} \mathrm{remained} \mathrm{about} \mathrm{the} \mathrm{same} \mathrm{between} \mathrm{the} \mathrm{screen} \mathrm{and} \mathrm{ceramic} \mathrm{cup} \mathrm{psychrometers}$ for different water potential gradients.

A more meaningful comparison of the relative responses of the screen and ceramic cup psychrometers to changing water potential was conducted in soil under severe evaporation conditions. Screen and ceramic psychrometers were taped together so that the sensors remained exposed, yet were adjacent to each other. These were buried in the soil of pots containing month-old corn plants that were rapidly transpiring. A copperconstantan thermocouple was buried with each pair of sensors to measure soil temperature. The pots were placed in an environmental growth chamber with a programed environment for air temperature at $25^{\circ} \mathrm{C} ., 0.5 \mathrm{cal} . \mathrm{cm} .^{-2} \mathrm{~min} .^{-1}$ radiation $(0.3$ to $3.0 \mu)$, windspeed at $45 \mathrm{~cm}$. sec.-1, and a vapor pressure deficit of $19 \mathrm{~mm}$. Hg. The soil was brought to saturation ( $\psi=0$ bars) initially, and then allowed to dry until severe wilting occurred 3 days later. During this period the psychrometers were read every few hours; the assumption was made that the soil water potential adjacent to the pair of psychrometers (a screen and a ceramic unit taped together) would be the same for both psychrometers. Outputs were converted to $25^{\circ} \mathrm{C}$. using equation (5) above. 
The water potential data were plotted in figure 10, and a regression analysis yielded an equation for a simple linear relationship between the two kinds of sensors. This relationship between sensors shows a definite lag in the response of the ceramic psychrometers as compared to the response of the screen psychrometers. At relatively high water potentials (above -2 bars) the ceramic psychrometers indicated a water potential of 0 bars, but the screen psychrometers were indicating values somewhat lower. As the water potential continued to decrease, the difference in the water potential values indicated by the two types of psychrometers increased. Within the growing range for most plants $(-0.5$ to -3.0 bars $)$, the ceramic psychrometers showed a $1 \mathrm{ag}$ of from 1 to 2 bars behind the screen psychrometers. The magnitude of this $1 \mathrm{ag}$ increased until at -30 bars the difference in the indicated soil water potential was about 8 bars.

These water potential data clearly show that once liquid contact is lost between the soil and the psychrometer, the ceramic cup offers a significant resistance to vapor exchange. Also, the magnitude of the resistance apparently increases as the ceramic cup dries. The rate of soil drying in this experiment was somewhat greater than might be expected under natural conditions, with the soil water potential decreasing from 0 to less than -30 bars over a 3-day period. 1t may be reasonable to assume that if the rate of drying was slower, the ceramic psychrometers would then be capable of maintaining a closer equilibrium with the true energy status of water in the soil. However, it should be noted that if the sensor offers a resistance to vapor exchange under rapidly changing water potential conditions, its use under natural conditions would be subject to error and question. The magnitude of this error would be a function of the resistance to vapor exchange imposed by the ceramic cup and the rate at which the soil water potential was changing. Therefore, from the standpoint of psychrometer response to a changing water potential, and the ease of construction, the screen psychrometer would seem to offer several obvious advantages over the ceramic cup psychrometer.

\section{DISCUSSION}

\section{Evaluation of Thermocouple Psychrometers}

Under conditions where the free energy status of water is changing rapidly, it is apparent that ceramic cup psychrometers lead to spurious estimates of water potential. This clearly points out the need to evaluate the response characteristics of instruments under the environmental conditions for which they are to be used. For instance, although the rate of soil drying under natural conditions may usually be somewhat less than reported for the data in figure 10, there are conditions where the soil water potential can be expected to decrease more rapidly. A decrease in soil water potential of over 30 bars in a few days is not unusual in the soil surface of high-elevation harsh sites where high radiation loads, steep vapor-pressure gradients, and high windspeeds are common. If ceramic cup psychrometers are used under natural conditions where a high rate of decreasing water potential can reasonably be expected, then erroneous data should be suspected, especially where water transfer occurs only in the vapor phase. Although the response-capability limits of screen psychrometers have not been determined, these instruments are free of the sources of error that affect the ceramic cup psychrometers.

The foregoing discussion suggests that there are several significant points to be considered in the evaluation of a thermocouple psychrometer which include: (1) the capability of distinguishing small differences in vapor pressure; (2) a linear response to water potential over the range of interest; (3) ease of construction and calibration; (4) a stable calibration with relatively long periods of use; and (5) the ability to respond to rapidly changing water potential conditions. The screen cup thermocouple psychrometer discussed above appears to meet all of these criteria. 


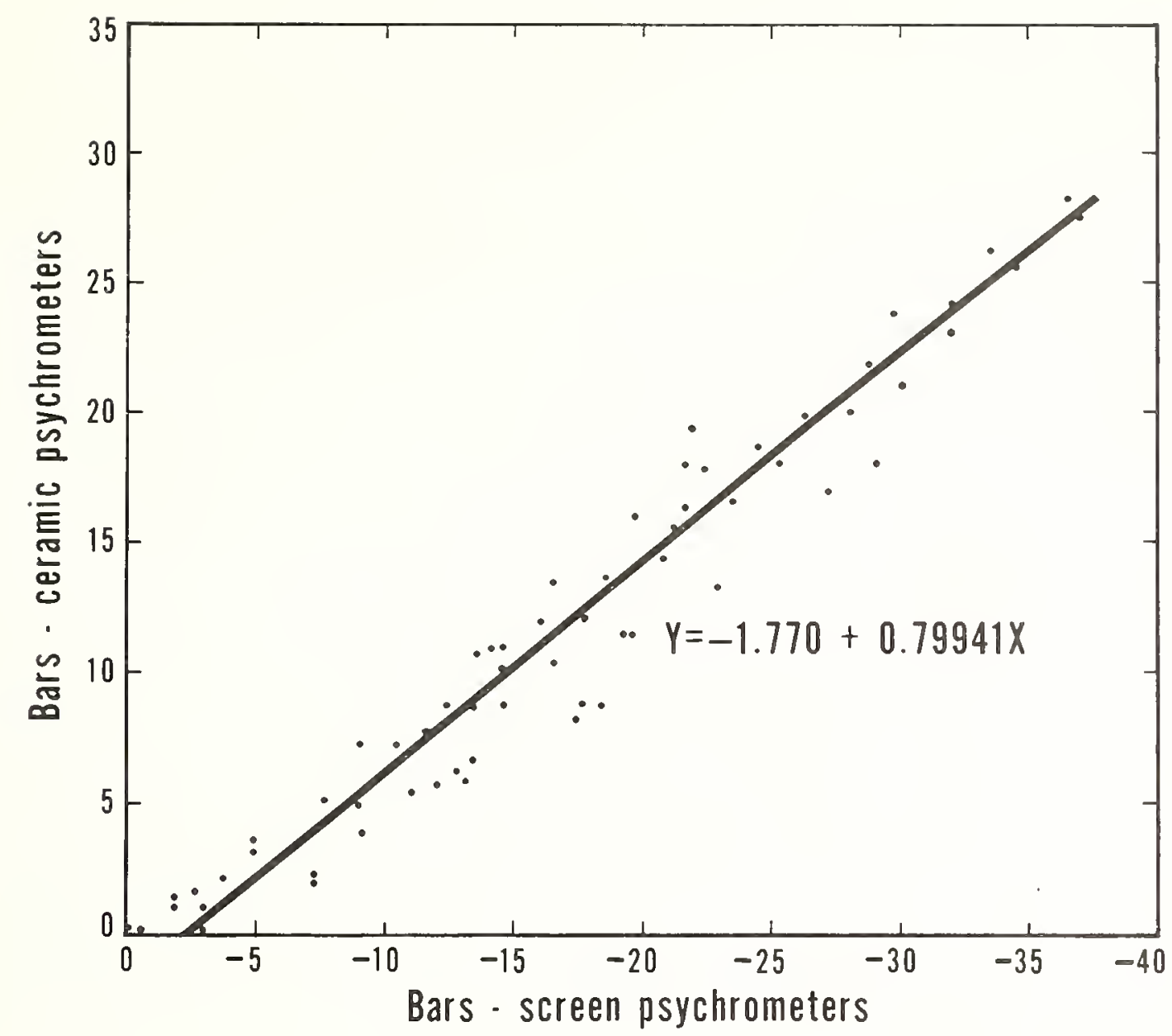

Figure 10.--Relationship of the response of the ceramic cup psychrometers to that of the screen psychrometers under high evaporation conditions $\left(r^{2}=0.933\right)$.

\section{Potential Uses of Thermocouple Psychrometers}

The screen cup psychrometer discussed here is particularly well suited for measurements of soil water potential. However, certain precautions must be observed because the copper lead wires are excellent heat conductors, and thermal gradients within the thermocouple may result if these are not damped out of the system. This damping can easily be accomplished by burying a short portion of the lead wire (several inches are usually enough) behind the thermocouple in the soil. For water potential measurements near the soil surface, the psychrometer should be buried in a position parallel to the surface so that a short length of the lead wire can also be buried for insulation against thermal gradients. Because the psychrometer output varies with temperature, a copper-constantan thermocouple (26 gage or smaller) should be attached to the psychrometer within the epoxy resin just above the screen cup so that psychrometer temperature at the time of reading can be determined.

The screen cup psychrometer is also well adapted for measuring the water potential gradients in stems of trees or large shrubs, using a technique similar to Wiebe and others (1970). Under this method, the sensing unit of the psychrometer is placed in carefully drilled holes to a depth of about $1 \mathrm{~cm}$. or less inside the cambium layer. The hole is then sealed with a waterproof compound to prevent evaporation and entrance of disease. The psychrometer and a short segment of the lead wires should be insulated with polyurethane foam or other insulating material to damp out temperature gradients. The smallest diameter stems that have been studied with this size of a psychrometer is $2 \mathrm{~cm}$., but with miniaturization of the psychrometer assembly it should be possible to work with much smaller stems. 
The most important application of thermocouple psychrometry will come from its further development and subsequent application to measurements of the water status in the soil-plant continuum under natural conditions. Previous attempts to understand the dynamic relationships between the energy status of water in soils and plants have been severely limited because the natural equilibrium was disturbed by removing samples from the system. It would appear that for in situ determinations of soil water potential and plant water potential of stems, the instrumentation presently available will provide accurate estimates of the energy status of water. This is not to say, however, that further improvements in the design and operation of thermocouple psychrometers are not needed. Certainly, the work of Hoffman and Splinter (1968a, 1968b), Rawlins and others (1968), and other workers, and particularly the development of the double-junction psychrometer, indicate that the in situ measurement of leaf water potential is now a definite possibility. My own experience with the double-junction psychrometer for measuring in situ leaf water potentials was very encouraging.

There are many possible applications of thermocouple psychrometers to research problems in all areas of the environmental sciences; only a few applications are described here. In research on physiological responses of plants under natural conditions, thermocouple psychrometry provides the best method for determining the diurnal and seasonal magnitudes of water potential gradients from the soil, through the plant stem, to the leaves. Psychrometers thus permit integrated field determinations of the water potential gradient throughout the soil-plant continuum. This capability has application in many areas of research, including: theoretical physiology and soil physics; range and forest revegetation; watershed; range; forest management research; fire control research; and, research in plant pathology. Thermocouple psychrometers appear to be primarily useful as research tools; however, at least one application to land management problems comes to mind. This application is in the area of fire-danger rating; the application of thermocouple psychrometers appears to offer an excellent opportunity for evaluating the potential flammability of live standing vegetation, ranging from large tree stems to fine leaf material. This would require some preliminary research, but the potential application is clear. There are, without doubt, other applications to land management problems; hopefully, the possibility of such applications will stimulate the imagination of the reader. 


\section{LITERATURE CITED}

Barrs, H.D.

1965. Comparison of water potentials in leaves as measured by two types of thermocouple psychrometer. Aust. J. Biol. Sci. 18: 36-52.

1968. Determination of water deficits in plant tissues. P. 235-368 in: Water Deficits and Plant Growth, Vol. 1. T. T. Kozlowski (ed.) New York: Academic.

Biggar, J.W., and S.A. Taylor.

1960. Some aspects of the kinetics of moisture flow into unsaturated soils. Soil Sci. Soc. Amer. Proc. 24: 81-85.

Boyer, J.S.

1967. Matric potentials of leaves. Plant Physiol. 42: 213-217.

Briggs, G.E.

1967. Movement of Water in Plants. 142 p. Philadelphia: F.A. Davis Co.

Campbell, G.S., W.D. Zollinger, and S.A. Taylor.

1966. Sample changer for thermocouple psychrometers: construction and some applications. Agron. J. 58: 315-318.

, J.W. Trul1, and W.H. Gardner.

1968. A welding technique for Peltier thermocouple psychrometers. Soil Sci. Soc. Amer. Proc. 32: 887-889.

Dalton, F.N., and S.L. Rawlins.

1968. Design criteria for Peltier-effect thermocouple psychrometers. Soil Sci. 105: $12-17$.

Gardner, W.R.

1965. Dynamic aspects of soil-water availability to plants. Annu. Rev. Plant

physiol. 16: 323-342.

Hoffman, G.J., and W.E. Splinter.

1968a. Instrumentation for measuring water potential of an intact plant-soil system. Amer. Soc. Agr. Eng. Trans. 11: 38-42.

, and W.E. Splinter.

1968b. Water potential measurements of an intact plant-soil system. Agron. J. 60: $408-413$.

Kramer, P.J., E.B. Knipling, and L.N. Miller.

1966. Terminology of cell-water relations. Science 153: 889-890.

Lang, A.R.G.

1968. Psychrometric measurement of soil water potential in situ under cotton plants. Soil Sci. 106: 460-464.

Letey, $J$.

1968. Movement of water through soil as influenced by osmotic pressure and temperature gradients. Hilgardia 39: 405-418.

Lopushinsky, W., and G. Klock.

1970. Construction details of ceramic bulb thermocouple psychrometers. Northwest Sci. Soc. Proc.

Merrill. S.D., F.N. Dalton, W.N. Herkelrath, G.J. Hoffman, R.D. Igvalson, J.D. Oster, and S.L. Rawlins.

1968. Details of construction of a multipurpose thermocouple psychrometer. U.S. Dep. Agr., U.S. Salinity Lab. Res. Rep. 115, 9 p.

Peck, A.J.

1968. Theory of the Spanner psychrometer. 1. The thermocouple. Agr. Meteorol. 5: $433-447$.

1969. Theory of the Spanner psychrometer. 2. Sample effects and equilibrium. Agr. Meteorol. 6: 111-124. 
Rawlins, S.L.

1966. Theory for thermocouple psychrometers used to measure water potential in soil and plant samples. Agr. Meteorol. 3: 293-310.

, and F.N. Dalton.

1967. Psychrometric measurement of soil water potential without precise temperature control. Soil Sci. Soc. Amer. Proc. 1967: 297-301.

, W.R. Gardner, and F.N. Dalton.

1968. In situ measurement of soil and plant leaf water potential. Soil Sci. Soci. Amer. Proc. 32: 468-470.

Richards, L.A., and G. Ogata.

1958. Thermocouple for vapor pressure measurements in biological and soil systems at high humidity. Science 128: 1089-1090.

Robinson, R.A., and R.H. Stokes.

1959. Electrolyte Solutions. 559 p. London: Butterworth.

Salisbury, F.B., and C. Ross.

1969. Plant Physiology. 747 p. Belmont, Calif.: Wadsworth.

Slatyer, R.O.

1967. Plant-Water Relationships. 366 p. New York: Academic.

, and S.A. Taylor.

1960. Terminology in plant-and soil-water relations. Nature 187: $922-924$.

Spanner, D.C.

1951. The Peltier effect and its use in the measurement of suction pressure. J. Exp. Bot. 11: 145-168.

1964. Introduction to Thermodynamics. 278 p. New York: Academic.

Taylor, S.A.

1964. Physics of irrigated soils: soil-plant water relations. Utah State Univ.

1965. Measuring soil-water potential. P. 149-157 in: Methodology of Plant Eco-physiology. Montpellier Symp. UNESCO Proc.

, and J.W. Cary.

1965. Soil-water movement in vapour and 1iquid phases. P. 159-165 in: Methodology of Plant Eco-physiology. Montpellier Symp. UNESCO Proc.

, D.D. Evans, and W.D. Kemper.

1961. Evaluating soil water. Utah Agr. Exp. Sta. Bul1. 426, 67 p. , and R.0. Slatyer.

1962. Proposals for a unified terminology in studies of plant-soil-water relations UNESCO. Arid Zone Res. 16: 339-349.

and G.L. Stewart

1960. Some thermodynamic properties of soil water. Soil Sci. Soc. Amer. Proc. 24: $243-247$.

Wiebe, H.H.

1966. Matric potential of several plant tissues and biocolloids. Plant Physiol. $41: 1439-1442$.

- (ed.)

Measurement of plant and soil water status. Utah State Univ. Agr. Exp. Sta. Bul1. (in press).

, R.W. Brown, T.W. Daniel, and E. Campbell.

1970. Water potential measurements in trees. Bioscience 20: 225-226.

Wilson, W.J.

1967. The components of leaf water potential. Aust. J. Biol. Sci. 20: $329-367$.

Zollinger, W.D., G.S. Campbe11, and S.A. Taylor.

1966. A comparison of water-potential measurements made using two types of thermocouple psychrometer. Soil Sci. 102: 231-239. 


\section{APPENDIX}

\section{Appendix 1}

Conversion of energy units to pressure units. The expression of chemical potential in energy units (ergs mole $\mathrm{e}^{-1}$ ) is inconvenient for discussions of soil-plant water relations. Therefore, we ordinarily deal with pressure units; the units of equation (2) are:

$\frac{\text { erg mole }}{\mathrm{cm} \cdot{ }^{3} \mathrm{~mole}^{-1}}=\operatorname{erg} \mathrm{cm} \cdot{ }^{-3}=$ dyne $\mathrm{cm} \cdot \cdot^{-1} \mathrm{~cm} \cdot{ }^{-3}=$ dyne $\mathrm{cm} \cdot \cdot^{-2}$

and:

1 bar $=0.987 \mathrm{~atm} .=10^{6}$ dyne $\mathrm{cm} \cdot \cdot^{-2}=10^{6} \mathrm{erg} \mathrm{cm} \cdot{ }^{-3}$

\section{Appendix 2}

Definition of terms commonly used in water relations:

e - The vapor pressure of water in the system under consideration at temperature $\mathrm{T}$, in $\mathrm{mm}$. $\mathrm{Hg}$

$\mathrm{e}_{\mathrm{o}}$ - The saturated vapor pressure of pure free water at temperature $\mathrm{T}$, in $\mathrm{mm}$. $\mathrm{Hg}$

$A_{W}-$ Relative water activity at temperature $T$

R - Universal gas constant, expressed as:

pressure units $=0.08205$ liter atm. $\mathrm{mole}^{-1}{ }^{\circ} \mathrm{K}^{-1}$

energy units $=8.3143 \times 10^{7} \mathrm{erg} \mathrm{mole}^{-1}{ }^{\circ} \mathrm{K}^{-1}$

$=8.3143$ joules mole $\mathrm{e}^{-1}{ }^{\circ} \mathrm{K}^{-1}$

$=1.987 \mathrm{cal} \cdot \mathrm{mole}^{-1}{ }^{\circ} \mathrm{K}^{-1}$

$\mathrm{T}$ - Absolute temperature ${ }^{\circ} \mathrm{K}\left(0^{\circ} \mathrm{C} .=273.16^{\circ} \mathrm{K}\right)$

$\bar{V}$ - The partial molal volume of water $\left(18.015 \mathrm{~cm} \cdot{ }^{3} \mathrm{~mole}^{-1}\right)$

$\psi$ - Total water potential, defined as the capability of the water in the system to do work compared with pure free water at the same temperature. Since the soil (or plant) water has a lower free energy (ability to do work) than pure water, it will be designated as a negative energy or pressure.

$\psi_{\pi}$ - Osmotic or solute potential, resulting from the presence of dissolved solutes which lower the free energy of water. This quantity will be designated as a negative pressure.

$\psi_{m}$ - Matric potential, resulting from the presence of colloids and adhesive surfaces of the soil matrix, and is a negative pressure.

$\psi$ - Pressure on turgor potential, resulting from the effects of positive pressure greater than atmospheric pressure, and is designated as a positive pressure. 


\section{Appendix 3}

Relative activities $\left(\mathrm{A}_{W}\right)$ and water potentials of $\mathrm{KCl}$ and $\mathrm{NaCl}$ solutions at $25^{\circ} \mathrm{C}$.

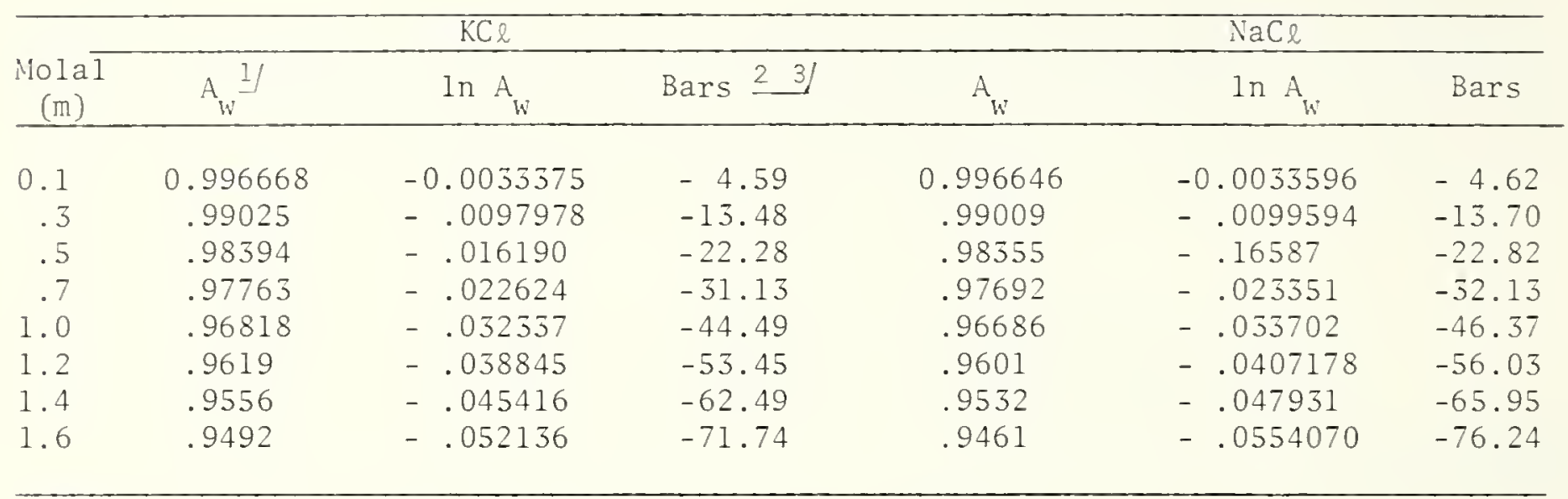

${ }^{1}$ Data for A taken from Robinson and Stokes (1959).

${ }^{2}$ Under normal atmospheric conditions the $\psi$ of a solution is equal to $\psi \pi$ because there are no other components affecting the free energy status of water in solution other than the solutes.

${ }^{3}$ The calculations of water potential were made using equation (2):

$$
\begin{aligned}
& -\psi=\frac{\mathrm{RT}}{\overline{\mathrm{V}}} \ln \frac{\mathrm{e}}{\mathrm{e}_{\mathrm{o}}} \\
& =\frac{\left(8.3145 \times 10^{7} \mathrm{ergs} \mathrm{mole} \mathrm{e}^{-1}{ }^{{ }^{\circ} \mathrm{K}^{-1}}\right)\left(298.16^{{ }^{\circ} \mathrm{K}}\right)}{18.016 \mathrm{~cm} \cdot{ }^{3} \mathrm{~mole}^{-1}}(\ln 0.996668) \\
& =\left(137.5994 \times 10^{7} \mathrm{ergs} \mathrm{cm} \cdot{ }^{-3}\right) \quad(-0.0033375) \\
& =-4.59 \times 10^{6} \text { ergs } \mathrm{cm}^{-3}=-4.59 \text { bars } \text {. }
\end{aligned}
$$

\section{Appendix 4}

Some of the manufacturers supplying instrumentation and equipment for application in constructing and using thermocouple psychrometers:

Thermocouple wire

Omega Engineering Inc. Box 4047, Springdale Station

Stamford, Conn. 06907

Leeds and Northrup Co. 4907 Stenton Avenue

Philadelphia, Pa. 19144
Thermo-Electric Co., Inc.

Saddle Brook

New Jersey 07662 
Thermocouples (chromel-constantan, 0.001 inch diameter)

Omega Engineering, lnc.

Box 4047, Springdale Station

Stamford, Conn. 06907

Voltmeters

Hewlett-Packard Co.

P.O. Box 301

Loveland, Colorado 80537

Electronic Components

Allied Electronics

5475 Leetsdale St.

Denver, Colorado 80222

Wire Screen

Star Wire Screen

4333 W. Clayton Avenue

St. Louis, Mo. 63110

Tefion

Plastic Products of Utah

2340 S.W. Temple

Salt Lake City, Utah 84115
Lepco $^{3}$

459 South Main Street

Logan, Utah 84321

Keithley Instruments, Inc.

28775 Aurora Road

Cleveland, Ohio 44139

Newark-Denver Electronics

Supply Co.

2170 S. Grape Street

Denver, Colorado 80222

${ }^{3}$ Lepco supplies the entire thermocouple psychrometer with an attached ceramic cup, together with a cooling circuit and voltmeter. 


\section{Appendix 5}

Circuit diagram and list of components required to construct the arc-welder unit for welding thermocouple psychrometers.

Quantity

1. Battery, 45 volt (i.e., Eveready No.762-S) . . . . . . . . . . . 1

2. Resistors

a. $250 \mathrm{ohm}, 5 \%$. . . . . . . . . . . . . . . . . . . . . . 1

b. 50 ohm, 1 turn, potentiometer ............. . . 1

3. Capacitor, 60 uf. . . . . . . . . . . . . . . . . . . . . 1

(For convenience the unit can be housed in an aluminum box.)

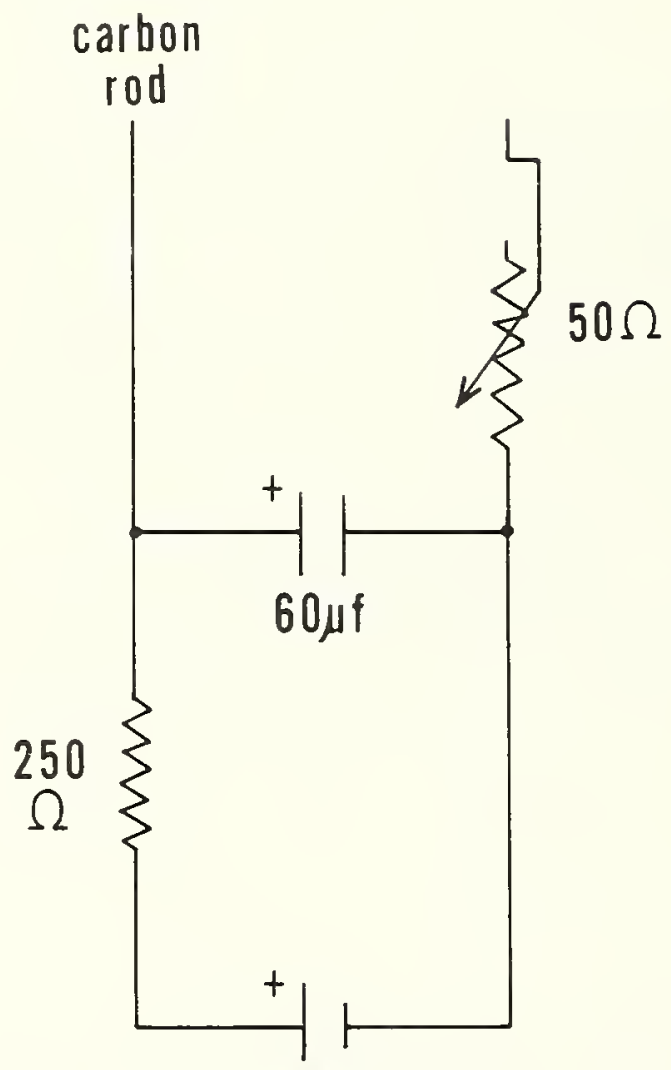

$45 v$ 


\section{Appendix 6}

Circuit diagram and list of components required to construct the "switchbox" cooling circuit for thermocouple psychrometers.

Quantity

1. Resistors (all resistors are $1 \%$ )
a. 82 ohms . . . . . . . . . . . . . . . . . . . . . . . . 1

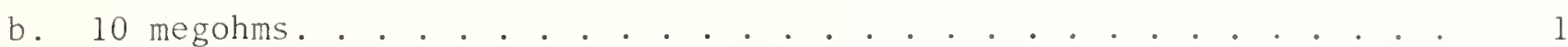

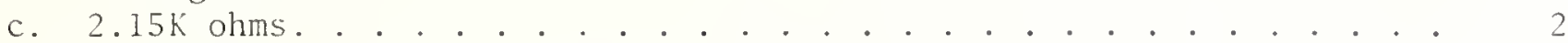
d. $1.0 \mathrm{ohm}$. . . . . . . . . . . . . . . . . . . . . . . . . 1
2. Trimner potentiometer, $5 \mathrm{~K}$ ohms. . . . . . . . . . . . . . . . . . . . . 1
3. Battery, 1.35 volt mercury. . . . . . . . . . . . . . . . . . . . 2
4. Potentiometer, $100 \mathrm{~K}$ ohms, 10 turn . . . . . . . . . . . . . . . . 1
5. Milliameter, DC . . . . . . . . . . . . . . . . . . . . . . . . 1
6. Switch, shorting rotary, 4 poles, 2-6 positions, 2 sections . . . . . 1

(Note: This assembly should be mounted in an insulated aluminum box similar to that shown in figure 7.)

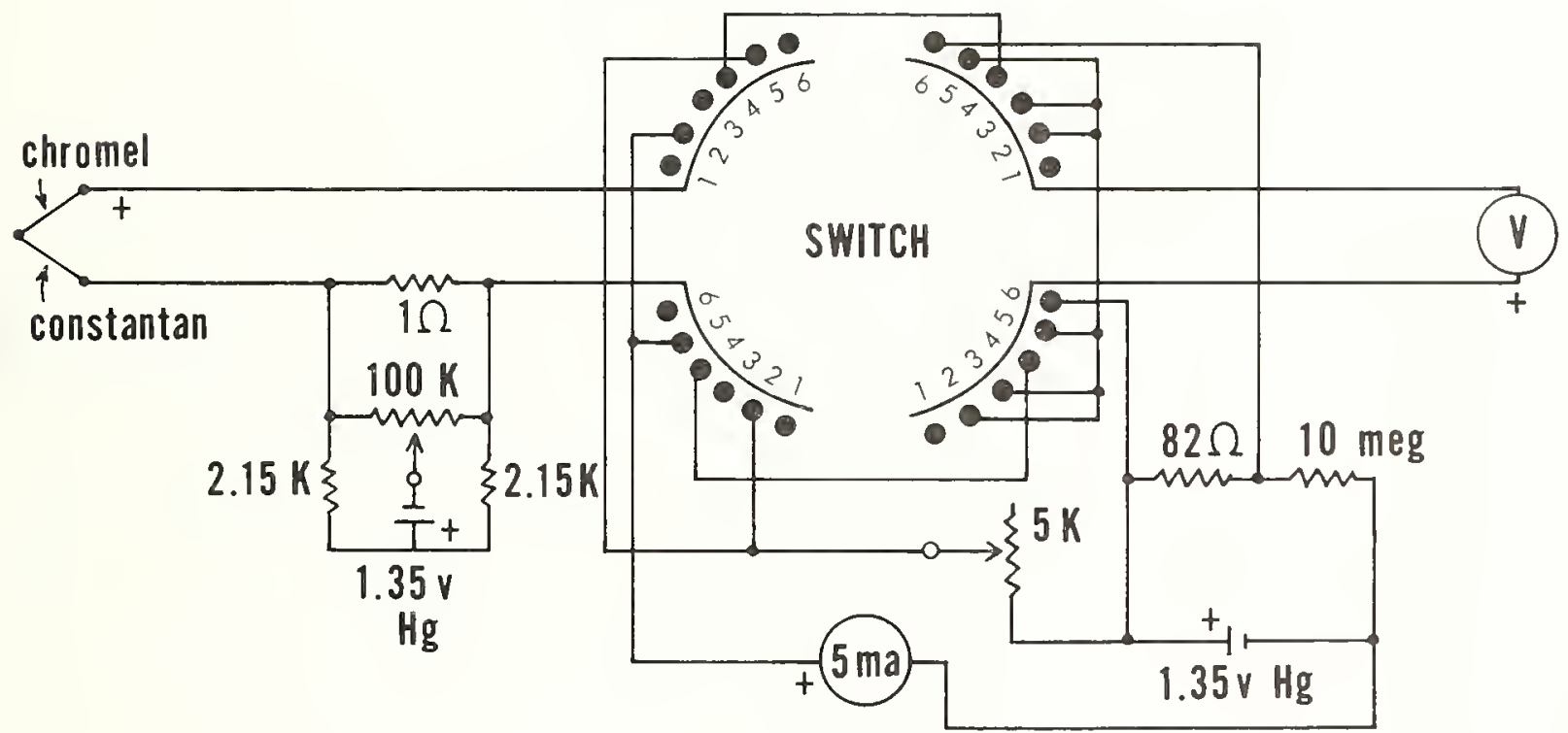




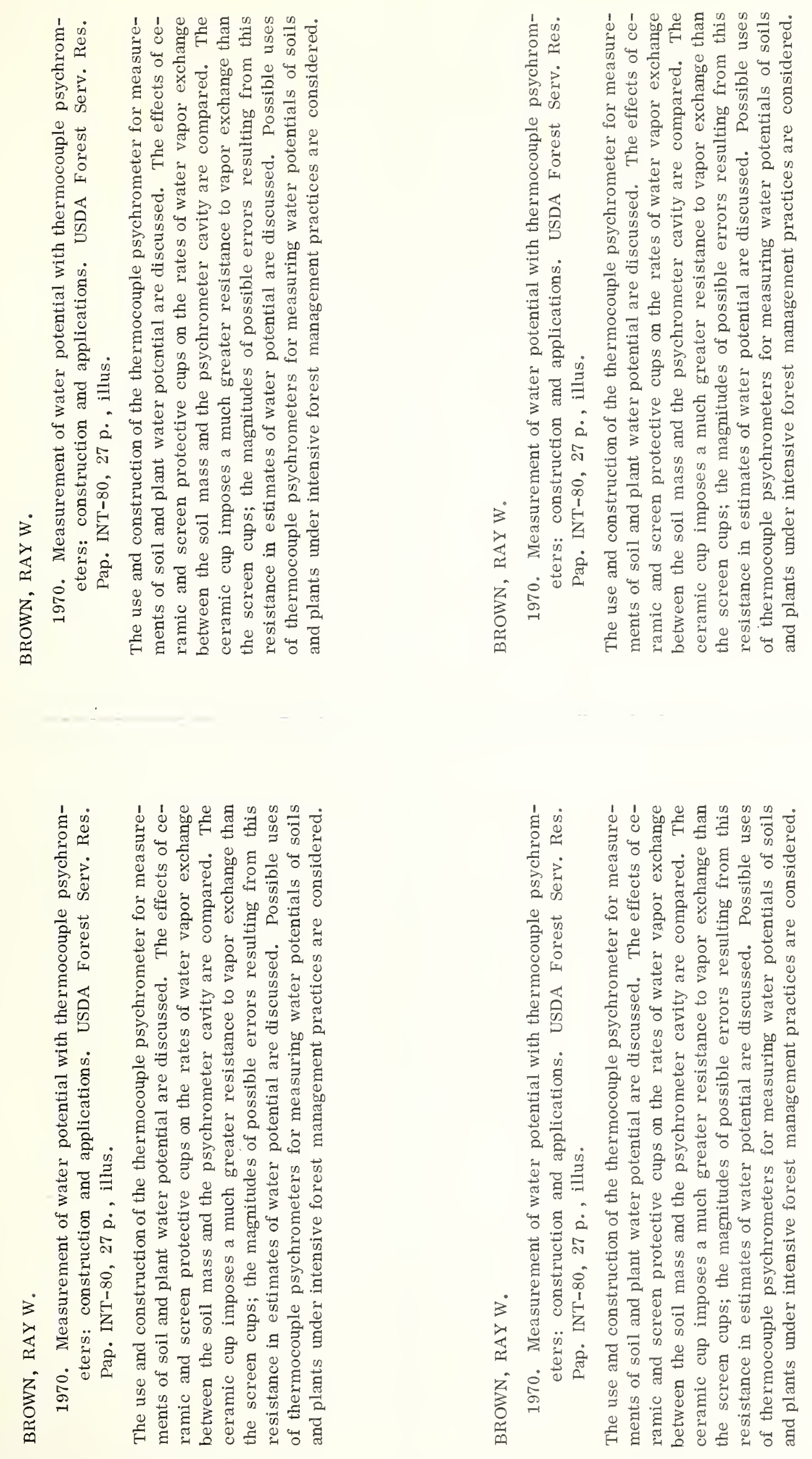

Headquarters for the Intermountain Forest and Range Experiment Station are in Ogden, Utah. Field Research Work Units are maintained in:

Boise, Idaho

Bozeman, Montana (in cooperation with Montana State University)

Logan, Utah (in cooperation with Utah State University)

Missoula, Montana (in cooperation with University of Montana)

Moscow, Idaho (in cooperation with the University of Idaho)

Provo, Utah (in cooperation with Brigham Young University) 
